\title{
Empresariado, parlamento e democracia: a CNI e o Congresso Nacional (2010-2017) ${ }^{1}$
}

\author{
Paulo Roberto Neves Costa ${ }^{2}$ \\ Igor Sulaiman Said Felicio Borck ${ }^{3}$
}

\begin{abstract}
Este artigo trata da relação entre empresariado e parlamento no Brasil, mais especificamente da agenda legislativa da Confederação Nacional da Indústria (CNI). O objetivo é verificar as particularidades do processo de constituição do empresariado industrial enquanto ator político no Congresso Nacional a partir de categorias analíticas voltadas para: 1- o processo institucional interno à CNI de definição de suas posições sobre os projetos; 2- a forma como a entidade descreve e avalia a sua relação com o parlamento; 3 - o cotejamento entre tais posições e os resultados do processo legislativo. Foram utilizados os documentos públicos da CNI, processados de forma quantitativa e qualitativa, considerando o período de 2010 a 2017. Verificamos que as particularidades da relação entre industriais e parlamento indicam: a complexidade do processo de constituição dos primeiros enquanto ator político no Legislativo; a importância dada por esse ator a tal processo; e o seu alto grau de satisfação com a forma e os resultados de sua relação com o Congresso Nacional, permitindo pensar sobre as características dessa instituição também à luz da relação que com ela estabelece um importante grupo da sociedade, bem como sobre o seu funcionamento concreto e as bases sociais da democracia no Brasil.

Palavras-chave: empresariado; Congresso Nacional; Confederação Nacional da Indústria; Seminário RedIndústria; lobby
\end{abstract}

\section{Introdução ${ }^{4}$}

A relação entre empresariado e Poder Legislativo federal já foi contemplada por parte da extensa literatura sobre os empresários no Brasil. Em geral, tais estudos se voltam para a atuação das entidades empresariais no processo legislativo e seu impacto no

\footnotetext{
1 Uma versão inicial deste artigo foi apresentada no $41^{\circ}$ Encontro da Anpocs, Caxambu, 2017: "Agenda legislativa da Confederação Nacional da Indústria no período da 54a e 55a legislatura federal".

2 Universidade Federal do Paraná - Departamento de Ciência Política, Curitiba (PR), Brasil.

E-mail: <paulocostaufpr@gmail.com>.

3 Universidade Federal do Paraná - Programa de Pós-Graduação em Ciência Política, Curitiba (PR), Brasil. E-mail: <iborcki@hotmail.com>.

4 Este artigo faz parte de projeto de Bolsa de Produtividade e de Projeto Edital Universal, ambos pelo CNPq, e está vinculado às atividades do Núcleo de Pesquisa em Sociologia Política do Departamento de Ciência Política da UFPR.
} 
processo decisório e a efetividade de suas ações na defesa de seus interesses ${ }^{5}$. Entretanto, poucos são os estudos que abordam o processo de construção das agendas de demandas e interesses. Trata-se de uma dimensão fundamental e que antecede a ação política propriamente dita, bem ou malsucedida, ou seja, o processo de definição da agenda de interesses e das estratégias visando influenciar, no caso, o processo legislativo, o qual, por sua vez, é antecedido por outro processo fundamental, a construção coletiva das posições e dos interesses desse grupo social ${ }^{6}$.

Essa dimensão interna ao empresariado e às suas entidades representativas, de um lado, diz respeito aos fatores correlatos às atividades empresariais propriamente ditas dos seus representados, ou seja, aquelas relativas à posição específica do grupo na produção e nas relações de mercado; e, de outro lado, remete aos contextos em que tais atividades são objeto de processos decisórios no âmbito do Estado. Entre essas duas dimensões da atividade empresarial, a da economia e a da política, existem processos internos às entidades representativas do grupo, institucionalizados em maior ou menor grau, além de outros procedimentos adotados por aqueles que as dirigem em um determinado momento, os quais são fundamentais no processo de definição daquela agenda de interesses e das eventuais estratégias de atuação na sua defesa, manifestas em seus padrões de ação política?.

Mesmo para a perspectiva que enfatiza a importância dos condicionantes externos como um elemento fundamental para a constituição do ator político coletivo (Olson, 1999), seria relevante analisar como o próprio grupo, no interior de suas instituições representativas, organiza a sua agenda de interesses.

Entretanto, a essa análise procuramos articular outra, qual seja, a da descrição e da avaliação feitas pelos próprios atores acerca de sua ação política e do resultado desta. Como argumentamos a seguir, entendemos que essa abordagem centrada no ponto de vista do ator pode trazer contribuições também para o desenvolvimento da agenda mais corrente sobre os empresários, ou seja, aquela que se refere ao seu poder ou influência política, exatamente por voltar-se para a forma como o próprio agente trata a sua ação e

\footnotetext{
5 Ver, por exemplo, Mancuso, 2004, 2007a; Oliveira e Onuki, 2010; Mancuso e Oliveira, 2002; Troiano, 2012, 2017; Doctor, 2002; Santos et al., 2015; Santos, 2011, 2014; Pont, 2008; Costa, 1998. Há também o trabalho de Pablo Cesário que indica a CNI e a CNC (Confederação Nacional do Comércio de Bens, Serviços e Turismo) como as únicas entidades empresariais que fazem parte do núcleo dos grupos de interesse mais atuantes, organizados e articulados no exercício do lobby no Congresso Nacional (Cesário, 2016) e o artigo de Donatello sobre a representação empresarial no Brasil e na Argentina (Donatello, 2017).

6 Além do já mencionado estudo clássico de Mancuso (2007a), Juliana Isac Campos analisa a estrutura interna da Federação das Indústrias do Estado de São Paulo (Fiesp) na sua atuação no Congresso Nacional (Campos, 2017), Andréa Cristina de Jesus Oliveira faz o mesmo considerando o caso da CNI (Oliveira, 2004) e Mariele Troiano trata da atuação empresarial nas comissões do Congresso Nacional (Troiano, 2017). Embora alguns se reportem ao processo de construção da agenda, esses estudos voltam-se mais propriamente para o exercício do lobby ou para a questão da força política dos empresários.

7 Por padrões de ação política estamos entendendo o conjunto de procedimentos, mais ou menos institucionalizados, adotados por um dado ator político na defesa de seus interesses. Entendemos que isso revela aspectos importantes do funcionamento efetivo das instituições políticas e do seu arranjo, o regime político, bem como das relações que esse ator estabelece com tal institucionalidade.
} 
os resultados desta e daquilo que entende ser a sua força política ${ }^{8}$. Portanto, nossa preocupação não é saber se os empresários são ou não bem-sucedidos, mas sim conhecer o modo como eles caracterizam e avaliam o resultado de sua ação. Em suma, é a partir dessas proposições que estudamos a relação entre a Confederação Nacional da Indústria (CNI) e o Congresso Nacional entre 2010 e 2017. A seguir, apresentamos nossas categorias analíticas. Posteriormente, comentamos os resultados de nossa pesquisa empírica à luz daquelas categorias analíticas. Por fim, apresentamos nossas considerações finais.

\section{Empresários e Legislativo: formato institucional, representação e convergência}

Como vimos acima, a questão de fundo deste artigo é a relação entre os empresários e as instituições políticas do regime democrático no Brasil. Mais particularmente, analisamos a relação entre uma entidade de representação sindical do empresariado industrial e o processo legislativo no âmbito federal. Nosso objetivo é refletir sobre a forma como os empresários industriais se preparam para a ação junto ao Congresso Nacional e como avaliam a sua relação com essa dimensão institucional fundamental do funcionamento da democracia brasileira nos dias de hoje. Portanto, não pretendemos fazer um estudo do exercício efetivo do lobby ou da capacidade de sucesso político no parlamento por parte da CNI, assunto já contemplado pelos trabalhos acima referidos, embora a análise aqui proposta vise também trazer contribuições para esse tipo de abordagem.

Nosso objeto é a agenda legislativa $(\mathrm{AL})$ da CNI e o período considerado vai de 2010 a $2017^{9}$. Analisamos os documentos dessa entidade a partir de três categorias: 1- o formato institucional ou as particularidades organizacionais do processo de definição dos interesses, posições e demandas que antecedem a ação política da CNI junto ao Congresso Nacional; 2- a representação, ou seja, a caracterização e a avaliação feitas pela própria entidade acerca de sua relação com o Congresso Nacional; e 3- o cotejamento entre as posições da CNI e o resultado das proposituras na Câmara dos Deputados e no Senado Federal. Tais categorias analíticas são apresentadas e desenvolvidas a seguir.

\section{O formato institucional da relação entre a CNI e o Congresso Nacional}

Através da categoria analítica formato institucional, procuramos estudar os aspectos institucionais internos, em especial aqueles formalizados, de processamento e

\footnotetext{
8 Para uma revisão do debate sobre a questão da força ou da debilidade política do empresariado no Brasil, ver Mancuso (Mancuso, 2007b).

9 Além de analisada em alguns dos trabalhos mencionados acima, a CNI foi objeto de estudos sobre empresariado, internet e política (Braga e Nicolás, 2009) e sobre empresariado e Legislativo (Santos, 2014; Troiano, 2017).
} 
construção das posições, demandas e propostas que uma entidade comporta quando enfrenta o desafio de exercer a representação de um dado grupo social. Essa articulação entre as dimensões social e institucional de um dado coletivo, quando este atua de forma organizada na defesa de seus interesses, é fundamental porque, ao mesmo tempo, reflete e impacta diretamente, de um lado, no processamento daquilo que seriam seus interesses e, de outro, na definição das formas de defendê-los, portanto, da constituição desse grupo enquanto ator político coletivo.

Isso significa que o formato institucional diz respeito tanto às condições sociais, econômicas e culturais do coletivo quanto aos aspectos institucionais do regime político. Daí a sua pertinência para a construção de uma estratégia de análise da ação de grupos sociais organizados e das suas relações com a institucionalidade política. Portanto, diz respeito aos padrões de ação política do grupo, mais particularmente os internos às entidades de representação de interesses, mas que se voltam para o contexto externo a elas e ao grupo. Em suma, remete às características institucionais da forma como a entidade produz suas análises, suas decisões e suas estratégias perante o processo decisório e o regime político vigente.

Não se trata de uma abordagem formalista de procedimentos institucionais, mas sim da verificação das formas como um dado grupo social equaciona internamente a sua própria existência enquanto ator político institucionalizado. Enfim, embora as entidades de representação não sejam a única forma de um grupo social atuar politicamente, é nesse processo que os indivíduos que compõem o grupo lidam com as questões concretas da ação coletiva e da luta política organizada. Além disso, tal processo se caracteriza não apenas pela aproximação e pela concertação, mas também por conflitos e tensões, os quais têm que ser processados através do formato institucional, o que, por sua vez, também é fortemente condicionado pelo contexto legal e institucional, ou seja, as leis e o regime político vigente. Isto é, o formato institucional, em especial nas democracias, nunca é totalmente controlado internamente ou totalmente isento de influências externas, sejam elas sociais, legais, institucionais ou culturais ${ }^{10}$.

Neste artigo não pretendemos abarcar todas as dimensões institucionais da ação política da CNI, mas sim abordar aspectos que são fundamentais para o nosso objetivo de estudar a relação entre essa entidade e o Congresso Nacional, e que expressam o processo de análise e posicionamento ante as proposições legislativas consideradas por ela própria importantes para os interesses dos seus representados.

\footnotetext{
10 Mariele Troiano analisa e mapeia a presença dos empresários através das suas entidades no Processo Constituinte (Troiano, 2012), portanto, estudando os determinantes institucionais externos àquilo que a autora identifica como "estrutura corporativista". Em outro trabalho, acima mencionado, Troiano trata da intermediação de interesses e da influência dos empresários através das audiências públicas na Câmara dos Deputados (Troiano, 2017). Embora abordando questão diversa da que aqui consideramos, a autora reforça a ideia de que os empresários vão evoluindo na sua forma de se relacionar com as instituições democráticas.
} 
Como indicado acima, pretendemos, através da caracterização de alguns aspectos institucionais da relação entre a CNI e o Congresso Nacional, verificar como uma importante entidade de representação do empresariado industrial vê e analisa sua própria relação com o Congresso Nacional e, através dele, com a democracia. Nesse sentido, a análise daquilo que seria o ponto de vista do próprio empresariado organizado é uma abordagem que tem no estudo da representação que os empresários fazem de suas posições, de sua ação e dos resultados do processo legislativo uma forma produtiva de compreender essa relação ${ }^{11}$.

Isso nos exime de definir a priori ou externamente quais seriam os interesses dos agentes estudados, de estabelecer se eles efetivamente seriam os autênticos representantes do grupo, de avaliar o seu comportamento a partir de modelos ou critérios históricos ou normativos ou de verificar o sucesso ou insucesso de suas ações. E, já como observado, estamos considerando apenas uma das dimensões e dos níveis da atuação política da CNI, dado que essa entidade também possui formas institucionais de acompanhamento do Poder Executivo Federal e da política em âmbito estadual.

Além disso, embora não proponhamos essa categoria como forma de obter uma descrição fidedigna da ação da CNI ou de mensurar sua força política, tal representação implica não meramente um conjunto de ideias e valores, mas diz respeito àquilo que os próprios atores apresentam para o debate público como sendo seus interesses e posições e à orientação das suas ações concretas e das suas relações com uma dimensão fundamental da institucionalidade democrática. Enfim, a representação remete à avaliação sobre sua própria condição de ator político e da instituição na qual atua. Entendemos que essa dimensão é fundamental para estudar a ação política dessa entidade de representação empresarial. Inclusive, como vemos no caso aqui considerado, a divulgação dessa representação faz parte dos padrões de ação política da CNI. Portanto, impacta a sua relação concreta com o parlamento e com a política.

A importância das ideias é assunto intensamente presente nas ciências sociais e na ciência política e a ocorrência de uma "virada ideacional" já é assunto dos analistas desde os anos 1990. Já em 1988, Ronald Inglehart colocava a questão da necessidade de um "renascimento" da cultura política, no qual o debate era com a abordagem institucionalista (Inglehart, 1988). Sobre essa questão, Perissinotto e Stumm destacam a contribuição do institucionalismo discursivo para o tratamento da questão das ideias na análise da política, enfatizando a importância do estudo da percepção que os agentes têm de si próprios. Entendemos que a CNI se aproxima daquilo que, segundo Perissinotto e Stumm, alguns autores relevantes da chamada "virada ideacional" chamam de policy

\footnotetext{
11 Podemos remeter aos comentários de Martin Bauer sobre análise de conteúdo, ao afirmar que um "texto" "é a representação e a expressão de uma comunidade que escreve" e a "expressão de um contexto" (Bauer e Gaskell, 2002).
} 
entrepreneurs, ou seja, "agentes que investem seus recursos (tempo, energia, reputação, dinheiro) para influenciar o processo decisório" (Perissinotto e Stumm, 2017, p. 135).

Não cabe aqui remeter a esse debate, mas isso reforça a importância da análise, de um lado, do processo de construção dos interesses e das estratégias de ação na sua defesa e, de outro, da avaliação ou percepção que o ator tem de sua própria ação e das suas relações com as instituições. Enfim, a ideia aqui é defender que a representação conta porque se refere ao processo de constituição do ator político e de seus interesses e à avaliação desse processo.

Além disso, a representação possui uma dimensão institucional interna, ou seja, mais autoral por parte do grupo e vinculada às suas condições econômicas, sociais, políticas e culturais de construção dos interesses, e outra externa, sobre a qual não tem controle, mas que é igualmente relevante, pois é o espaço em que se atua na defesa daqueles interesses. Por isso, a representação dessas duas dimensões é importante para a análise do ator político em si, da política e das instituições nas quais atua. No caso deste artigo, a categoria representação remete a um momento específico, ou seja, a percepção acerca do resultado da relação com determinada dimensão institucional da democracia.

Em suma, a noção de representação não remete à clássica questão da representação política e apenas pretende apreender como um dado ator institucional caracteriza e analisa a sua atuação ante situações nas quais se vê em função do seu objetivo de definir e defender o que seriam os interesses do grupo social do qual se coloca como representante, diante da institucionalidade democrática. Por fim, a verificação da representação se dá através dos documentos da CNI nos quais se expressam a avaliação da entidade em relação ao Legislativo Federal, sua situação nesse processo e os resultados obtidos.

\section{O cotejamento entre as posições da CNI, a representação e o resultado do processo legislativo}

Associada às categorias de formato institucional e de representação, estamos trabalhando com a de convergência, através da qual comparamos o que o agente estabelece como seus interesses, objetivos, posições e avaliações e o resultado efetivo do processo decisório, no caso, legislativo.

Obviamente, uma entidade representativa tem como propósito agir no sentido de influenciar o processo decisório de forma favorável àquilo que seriam os interesses do coletivo representado, o que remete à questão da relação entre a ação e o resultado desse processo. Como vimos, a análise da ação efetiva, do grau de sucesso ou da força política de um determinado ator pressupõe, em primeiro lugar, a ocorrência de sua ação e, em segundo lugar, que tal ação e as relações de causa e efeito correlatas possam ser verificáveis e passíveis de algum tipo de mensuração. Tal análise ficaria ainda mais completa se houvesse a possibilidade de comparação com a forma como isso se daria com 
outros atores, dado que as ações políticas são essencialmente relacionais, porém ela ultrapassa os objetivos deste artigo.

Entretanto, o cotejamento entre o que o próprio ator político estabelece como seus interesses e o resultado do processo político contribui para a compreensão da sua relação com as instituições políticas, dado que significa uma forma de estudar a representação, que é uma dimensão que está sob o controle do ator, em comparação com um processo sobre o qual visa influenciar mas não controla. Assim, embora não pretendamos tratar do poder, da influência ou da força política desse grupo, essa comparação pode trazer contribuições importantes para o enfrentamento dessa questão, em primeiro lugar, por evitar correlações temerárias entre demandas ou interesses e resultados e, em segundo lugar, por relacionar a caracterização e a avaliação que o agente faz de sua própria ação e os resultados do processo no qual se deu essa ação.

Portanto, é uma forma de construir procedimentos analíticos que contribuem para pensar formas eficazes de tratar de correlação ou correspondência entre ação e resultado, no caso, a partir de uma dimensão constitutiva da própria ação, que é a representação, articulada à realidade do processo político. Afinal, o ponto de vista do agente sobre si próprio é um elemento crucial na definição da forma como ele efetivamente se relaciona com os diversos processos sociais, econômicos e políticos e com as instituições correlatas.

\section{A relação entre a CNI e o Congresso Nacional (2010-2017)}

As características gerais dos aspectos institucionais e dos documentos produzidos pela CNI para divulgação pública de suas posições em relação ao processo legislativo do Congresso Nacional são apresentadas brevemente abaixo. As fontes utilizadas na pesquisa são os próprios documentos disponibilizados na página eletrônica da $\mathrm{CNI}^{12}$, no caso, os relatórios e as prestações de conta. Nos relatórios, a entidade estabelece a relação entre as proposituras e os seus interesses e, na prestação de contas, apresenta suas análises do processo legislativo e de seu resultado ${ }^{13}$.

Quanto às questões que guiaram o tratamento dos documentos da CNI, em primeiro lugar, buscamos verificar o que eles revelam acerca do formato institucional que caracteriza a relação entre a CNI e o Congresso Nacional. Em segundo lugar, analisamos a representação, ou seja, como a CNI caracteriza e avalia sua relação com o Congresso Nacional. Por fim, a partir de um dado conjunto de variáveis, fazemos o cotejamento entre as posições adotadas pela CNI e as proposituras legislativas finalizadas.

\footnotetext{
12 Disponíveis em: <http://www.portaldaindustria.com.br/cni/> e em <http://www.portaldaindustria.com.br/cni/canais/agenda-legislativa-home/>. Acesso em: 15 jun. 2017. 13 Os relatórios da CNI relativos à AL são publicados anualmente, porém eles pretendem tratar de todos os interesses da indústria no Congresso Nacional até o momento de sua publicação. Os relatórios seguem o ritmo da tramitação das proposituras em cada casa legislativa federal. Assim, nos oito anos da AL estudados, encontramos projetos que tramitam desde 1989 e projetos que são aprovados no mesmo ano de sua apresentação.
} 


\section{O formato institucional da ação parlamentar da CNI}

Em primeiro lugar, o processo de construção das posições e das demandas da CNI junto ao Congresso Nacional tem na sua agenda legislativa $(A L)$ o momento fundamental de sua relação com o Legislativo federal. Segundo a CNI, "desde 1996, a Agenda apresenta à sociedade as principais proposições legislativas em tramitação na Câmara dos Deputados e no Senado Federal que afetam o desenvolvimento do país"14. A entidade remete o surgimento da AL e do Seminário RedIndústria, sobre o qual falamos a seguir, a três fatores: o processo de retomada da democracia no Brasil pós-1988, o contexto político de meados dos anos 1990 e o enfrentamento da questão do "custo Brasil".

Em segundo lugar, tais aspectos são tidos como parte de um processo de valorização da ação da entidade no Congresso Nacional:

A Agenda Legislativa da Indústria é o resultado da consolidação da consulta realizada pela CNI às 27 Federações de Indústrias e às Associações Setoriais de caráter nacional. A CNI encaminha às entidades as proposições legislativas de interesse do setor industrial apresentadas no Congresso Nacional durante o ano e as proposições priorizadas na Agenda Legislativa do ano anterior que continuam em tramitação. As entidades consultadas elegem as proposições mais importantes e o respectivo posicionamento sugerido. No Seminário RedIndústria, representantes das federações de indústrias e associações elegem os temas e proposições legislativas que comporão a Agenda Legislativa da Indústria, e que será submetida à aprovação dos diretores da CNI. Após a aprovação da Diretoria da CNI, a Agenda Legislativa da Indústria é publicada e fica à disposição de parlamentares e da sociedade civil ${ }^{15}$.

A CNI promove o Seminário RedIndústria desde meados dos anos 1990, através do qual são escolhidas as proposições legislativas e sugeridos os respectivos posicionamentos, que vão compor a $\mathrm{AL}^{16}$. Os posicionamentos resultantes desse processo

14 Disponível em: <http://www.portaldaindustria.com.br/cni/canais/agenda-legislativa-home/sobreagenda-legislativa/>. Acesso em: 25 abr. 2018.

15 As informações sobre a AL foram retiradas da página eletrônica da CNI: <http://www. portaldaindustria.com.br/cni/canais/agenda-legislativa-home/sobre-agenda-legislativa/>. Acesso em: 30 mar. 2016.

${ }^{16}$ Apenas a título de ilustração, segue um trecho do regimento do Seminário RedIndústria: "Art. 50 Será realizado anualmente um Seminário para eleição das proposições legislativas e respectivos posicionamentos que integrarão a Agenda Legislativa da Indústria. § 10 Participarão do Seminário, representantes das Federações, Associações e demais entidades industriais. § $2^{\circ}$ Os trabalhos do Seminário serão desenvolvidos em grupos temáticos e reunião plenária. § $3^{\circ}$ Os trabalhos dos grupos temáticos terão por base a consolidação das priorizações e dos posicionamentos definidos nas fichas de consulta encaminhadas à CNI no prazo previsto. $\S 4^{\circ} \mathrm{A}$ reunião plenária validará as decisões dos grupos temáticos, elegendo as proposições que deverão compor a Agenda Legislativa. $\S 50 \mathrm{O}$ documento final será submetido à Diretoria da CNI, que poderá aprová-lo integral ou parcialmente, nesse caso adicionando ou excluindo proposições, ou efetuando outras alterações que julgar necessárias". 
são submetidos à diretoria da entidade e se expressam na $A L$, cujo lançamento é anual e se caracteriza pela promoção de um grande evento que reúne diversas autoridades do Poder Executivo e do Congresso Nacional em Brasília, entre eles o presidente da República e o presidente do Congresso Nacional.

Desse seminário participam os diretores da CNI e os representantes das federações e das associações convidadas e o objetivo é definir uma pauta de interesses e posições políticas unificadas em relação às proposituras legislativas em tramitação no Congresso Nacional17. Enfim, esse aspecto do formato institucional mostra o esforço de mobilização coletiva, de ação coordenada e de organização da representação daqueles que seriam os interesses de todos os segmentos industriais ${ }^{18}$.

Assim, a AL é um esforço institucional e fruto de um trabalho de natureza participativa realizado pela CNI através do RedIndústria. Todos os participantes ganham uma ficha de inscrição e um login para acesso on-line a uma base de dados, chamada Legisdata, na qual podem apresentar os projetos que consideram importantes, com as devidas justificativas, estabelecer níveis de prioridade, além de apresentar uma proposta de posicionamento. As inserções feitas pelos participantes são consideradas até o momento do Seminário RedIndústria e discutidas em grupos específicos.

Outro aspecto institucional importante é a Diretoria de Relações Institucionais, responsável pela formulação e pela execução da $A L$, que se materializa na forma de relatórios elaborados anualmente. Esses relatórios anuais, por sua vez, têm como objetivo apresentar à sociedade as principais proposituras legislativas em tramitação na Câmara dos Deputados e no Senado que afetariam a indústria no país, bem como os posicionamentos adotados pela AL. Tomando por referência o que seriam os interesses de seus associados, a CNI classifica as proposituras legislativas da seguinte forma: convergentes, convergentes com ressalvas, divergentes, divergentes com ressalvas, tramitadas e não tramitadas.

O processamento das proposituras se dá a partir das seguintes variáveis:

Poder ou Casa Legislativa autora do projeto;

Sigla/Ano do projeto;

Nome do parlamentar autor;

Partido do parlamentar;

Estado do parlamentar;

Ponto de tramitação da propositura;

\footnotetext{
17 Objetivos da agenda expressos no regimento do fórum RedIndústria em 2017 são: Art. $3^{\circ}$ Os objetivos da Agenda Legislativa são: I - apresentar ao Congresso Nacional e à sociedade, com transparência, o entendimento da Indústria sobre temas e proposições legislativas relevantes para o segmento industrial e para o País; II - apoiar a participação empresarial na discussão dos assuntos legislativos que afetem o interesse do setor industrial e contribuir com o Congresso Nacional para a adoção de políticas públicas que propiciem o crescimento sustentado da economia; III - constituir-se em publicação orientadora do relacionamento da CNI, Federações, Associações e demais entidades industriais com o Congresso Nacional. 18 Wagner Mancuso já chamava a atenção para esse processo em seu trabalho sobre o lobby da indústria no Congresso Nacional (Mancuso, 2007a).
} 


\section{Posição da CNI;}

Resumo do tema e do assunto do projeto.

Em nossa pesquisa consideramos também a chamada Pauta Mínima (PM):

(...) uma lista restrita de proposições de alto impacto no ambiente de negócios do país, definidas e referendadas pelas entidades participantes da RedIndústria e do Fórum Nacional da Indústria. São projetos-alvo de uma ação sistemática e ambiciosa por parte da CNI e seus parceiros na criação de condições para conclusão da votação dessas matérias dentro do menor prazo $^{19}$.

(...) a Pauta Mínima lista as propostas que a indústria considera de alto impacto, positivo ou negativo, no ambiente de negócios (CNI, 2012, p. 13).

A Pauta Mínima resulta do próprio processo de participação dos industriais através de ferramentas on-line e durante o Seminário RedIndústria acima descrito, e é importante porque expressa, do ponto de vista dos próprios participantes, o que seria prioritário e que deveria receber maior atenção e atuação da entidade, além de condensar todo o processamento de interesses, demandas, propostas e queixas feitos pelo Seminário RedIndústria e pela AL em uma agenda prioritária, embora sua versão final tenha que ser aprovada pela diretoria da CNI.

Por fim, também enquanto parte dos relatórios, a AL produz outro conjunto de elementos fundamentais para os nossos interesses, que é o Prestando Contas, que contempla as informações acima mencionadas e uma avaliação daquilo que se entende como os resultados das proposituras contempladas pela $A L$, e que é fundamental para o tratamento das outras categorias analíticas aqui propostas: a representação e a convergência. A CNI descreve o Prestando Contas da seguinte forma:

Para se construir uma radiografia precisa de como avançam temas estratégicos para o setor produtivo, a Confederação Nacional da Indústria (CNI) oferece o Prestando Contas. Esta publicação apresenta e analisa o progresso da Agenda Legislativa e o resultado prático de deliberações do Senado Federal e da Câmara dos Deputados. Nesta edição, o Prestando Contas retrata os resultados do primeiro semestre da nova legislatura. A avaliação compara a posição de cada proposta, o status dos projetos na data da publicação da Agenda Legislativa 2015, realizada em março, e sua situação atual. O leitor pode, ainda, se informar sobre a atuação da CNI sobre cada proposição prioritária. Como inovação, o Prestando Contas 2015 será publicado somente em formato eletrônico. O documento poderá ser

19 Disponível em: <http://www.portaldaindustria.com.br/cni/canais/agenda-legislativa-home/sobreagenda-legislativa/>. Acesso em: maio 2017. 
consultado no Portal da Indústria e estará disponível para download. Para o futuro próximo, a publicação poderá ser acessada por aplicativo em dispositivos móveis (celular e tablet) e terá atualização mensal" (CNI, 2015, p. 25).

Em suma, entendemos que o Seminário RedIndústria, a $\mathrm{AL}$, a Pauta Mínima (PM) e o Prestando Contas são aspectos institucionais relacionados ao processamento dos interesses, das demandas e das estratégias de ação dos industriais que atuaram em tais espaços institucionais, portanto de sua própria constituição enquanto ator político, no caso, no processo legislativo federal. Em função disso, revelam aspectos institucionais e políticos internos complexos e importantes para a construção da representação.

A iniciativa de realizar o RedIndustria e produzir a AL e a PM, bem como a forma participativa que se pretendeu dar ao processo e a iniciativa de fazer o Prestando Contas, mostra a preocupação e o esforço da CNI em enfrentar os problemas decorrentes, de um lado, da diversidade de características e de interesses do setor industrial e, de outro, da forma de articular tais interesses no âmbito do processo legislativo. Portanto, esse aspecto institucional é interessante porque diz respeito a essas duas dimensões da relação entre empresários industriais e democracia, as quais remetem à organização dos conflitos internos, à definição de uma agenda de demandas e posições, à ação concreta na defesa de tais interesses nas instituições democráticas e ao envolvimento da entidade e do grupo social correlato com a prática do jogo legislativo da democracia.

Outro aspecto importante do formato institucional é o fato de que as decisões finais relativas à $\mathrm{AL}$ e à $\mathrm{PM}$ passam pelos diretores da CNI, em particular aqueles que ocupam a Diretoria de Relações Institucionais e o Conselho Temático de Assuntos Legislativos $(\text { Coal })^{20}$. Mas o órgão que opera e produz a AL e que organiza o Seminário RedIndústria é a Subdiretoria de Assuntos Legislativos (CAL), que é ocupada exclusivamente por técnicos, formados em diversas áreas, como direito, ciência política e relações internacionais. Isso remete a outro aspecto relevante do formato institucional, ou seja, o processo de especialização e profissionalização do corpo técnico, o que certamente impacta no processo de definição das posições políticas da CNI. Enfim, a sistemática adotada e formalizada nos estatutos e na prática da CNI mostra uma preocupação com a institucionalização e a

\footnotetext{
20 Schneider (2010) e Oliveira (2004) já chamavam a atenção para a importância do Coal e de suas particularidades. As atribuições do Coal são estabelecidas da seguinte forma: "Analisa e orienta a ação política da CNI no Congresso Nacional, com foco no acompanhamento e na defesa de interesses no processo legislativo. Além disso, articula apoio político a projetos importantes para o setor industrial, divulga posições da CNI sobre os projetos em tramitação e participa do processo de formulação da Agenda Legislativa da Indústria". Disponível em: <http://www.portaldaindustria.com.br/cni/institucional/conselhos-tematicos/> . Acesso em: 15 jun. 2017.
} 
EMPRESARIADO, PARLAMENTO E DEMOCRACIA: A CNI E O CONGRESSO NACIONAL (2010-2017)

qualificação de um processo deliberativo que ultrapassa em muito a própria entidade ${ }^{21}$. Voltaremos a essa questão mais adiante.

\section{A representação da CNI sobre a sua relação com o processo legislativo}

Nada menos do que $63 \%$ da Pauta Mínima se movimentou de acordo com os interesses da indústria este ano, contra 52\% da Pauta Mínima de 2011 no primeiro semestre do ano passado (CNI, 2012, p. 13).

No primeiro semestre, $71 \%$ da Pauta Mínima evoluiu de acordo com os interesses da indústria (CNI, 2013, p. 13).

Há uma significativa correlação entre os debates travados no Congresso Nacional e as propostas de interesse da indústria brasileira. (...) Como se observará a seguir, este foi um semestre de movimentação e avanços importantes para a pauta legislativa da indústria brasileira (CNI, 2015, p. 25).

Quando se analisam as discussões e deliberações do Congresso Nacional neste primeiro semestre, percebe-se que a pauta prioritária da indústria mantém destaque no dia a dia legislativo, confirmando tendência do Prestando Contas desde 2011. Mais uma vez, buscou-se alinhar as prioridades ao momento econômico e político do país, fator que se refletiu no avanço significativo de projetos conforme a posição do setor industrial, na comparação com aqueles divergentes aos interesses da indústria. Neste primeiro semestre, o Prestando Contas identificou que $62 \%$ das proposições de interesse avançaram em consonância com os anseios da indústria. A marca é a mais elevada da série histórica e representa um avanço considerável em relação ao mesmo período de 2014. Quando se desconsideram os que permaneceram com tramitação inalterada, os resultados se mostram mais positivos: $68 \%$ das propostas que evoluíram, o fizeram de forma favorável e as 32\% restantes, caminharam no sentido contrário (CNI, 2015, p. 26-27) (grifos nossos).

\footnotetext{
21 Mais uma vez, o regimento do RedIndústria indica como isso se dá: "Art. 12 - Na abertura da sessão plenária, o Gerente Executivo da Unidade de Assuntos Legislativos determinará a ordem de apresentação dos grupos. Parágrafo único. As priorizações dos grupos para o tema "Indicações Setoriais" serão avaliadas pelo Plenário, de forma consolidada, após a apresentação do último grupo. Art. 13 - O relator de cada grupo temático terá até 45 minutos para apresentar a relação das proposições recomendadas para constar da Agenda, com a leitura dos sumários e da opção de convergência ou divergência e eventuais ressalvas. $\S 1^{\circ}$ Havendo divergência quanto às conclusões dos grupos, qualquer participante do Seminário poderá propor inclusão ou exclusão de proposição ou ainda modificação de posicionamento, mediante manifestação verbal em período máximo de dois minutos. $\S 20$ Havendo interessados em discutir a proposta, será concedida a palavra, pelo prazo de dois minutos, para, no máximo, dois oradores manifestarem-se a favor e dois contra. $\S 3^{\circ}$ Caso não haja consenso após as manifestações, a proposta será submetida a votos, cabendo a cada entidade presente um voto. $\S 4^{\circ}$ As votações poderão ser por manifestação simbólica. $\S 5^{\circ}$ Será declarada vencedora a posição que obtiver a maioria de votos dos presentes com direito a voto".
} 
Essas passagens ilustram parcialmente as avaliações que a CNI faz de sua relação com o processo legislativo no Congresso Nacional. Podemos perceber, em primeiro lugar, a importância que a entidade dá ao processo legislativo federal nos documentos que sintetizam os resultados de sua atuação parlamentar. Em segundo lugar, a avaliação significativamente positiva, e crescente ao longo do tempo, chega a ser quantificada e produzida pela própria CNI, como pode ser confirmado com o Gráfico 1, retirado dos documentos da entidade:

\section{Gráfico 1}

Tramitação dos projetos da pauta mínima $X$ interesse da indústria (10 semestre de 2011 a 2015)

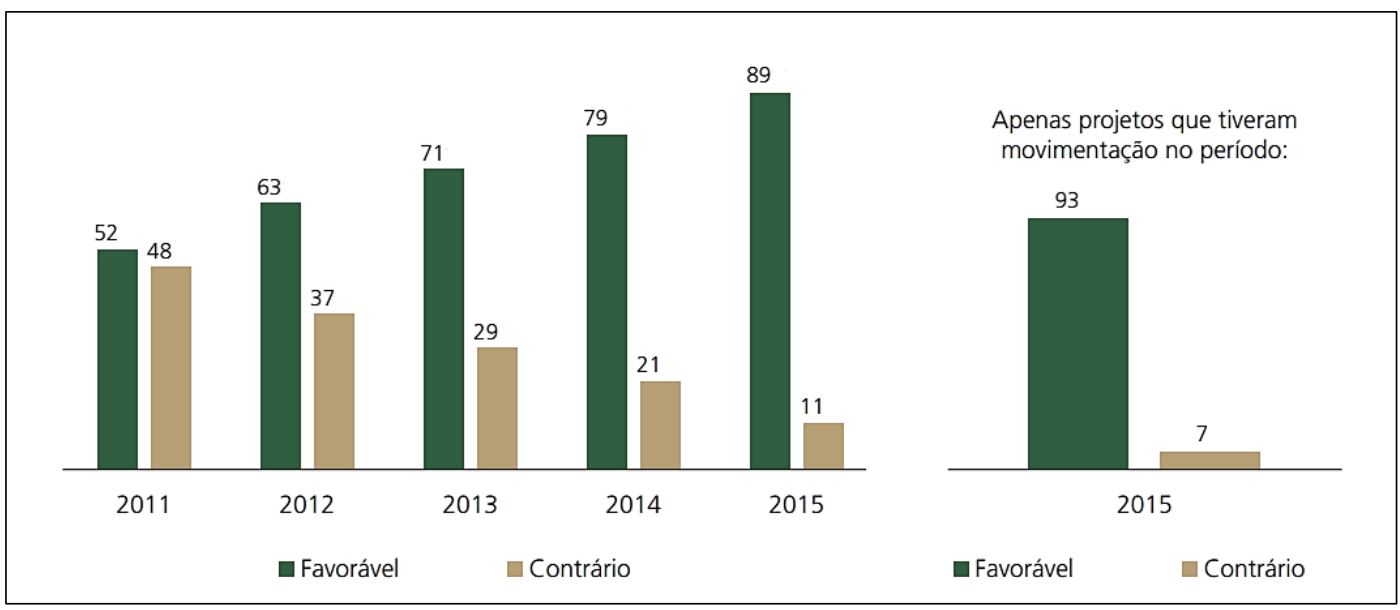

Fonte: CNI (2015), p. 26.

E a importância dada para os projetos da Pauta Mínima remete a uma sensação de sucesso também em relação a essa inovação no formato institucional. Há também uma avaliação positiva do funcionamento do Congresso Nacional até mesmo quando não há decisão legislativa. Mais uma vez, isso é ilustrado de forma gráfica e quantificado pela própria CNI, como mostra o Gráfico 2. Além disso, a entidade afirma que atuou também no âmbito das comissões do Congresso Nacional, expondo aspectos de seus padrões de ação política 22 .

22 "O Prestando Contas identifica, ainda, avanços na pauta de interesse da indústria em projetos não incluídos na Agenda Legislativa 2015. Foi aprovado em comissão especial e está pronto para votação no Plenário da Câmara dos Deputados o projeto que prorroga prazo para que empresas inscritas no Supersimples tenham o direito de parcelar débitos fiscais (PLP 25/2007), tema contemplado na Agenda com o PLS-Complementar 476/2013" (CNI, 2015). 


\section{Tramitação dos projetos da agenda legislativa $X$ interesse da indústria ( $1^{\circ}$ semestre de 2011 a 2015 )}



Fonte: CNI (2015), p. 27.

O trecho a seguir também é interessante como ilustração da representação que a entidade faz da sua relação com o Congresso Nacional:

Diferentemente do total de projetos da Agenda Legislativa, quando analisamos apenas os projetos de interesse setorial, é possível perceber uma pequena margem de prevalência de proposições consideradas contrárias pela CNI ao interesse da indústria. No entanto, apesar de ainda prevalecer esse caráter reativo, a Agenda setorial aproxima-se do equilíbrio (CNI, 2012, p. 18).

A representação da CNI a respeito de sua relação com o Congresso Nacional também leva em conta os aspectos conjunturais do processo político, a preocupação em ter uma postura mais ativa do que reativa, a questão da relação entre Executivo e Legislativo e a consideração da questão da origem dos projetos, como indicam os trechos abaixo:

Se ano eleitoral costuma naturalmente desmobilizar o Congresso, em particular no segundo semestre, essa provável desaceleração foi satisfatoriamente compensada nesses primeiros seis meses, como mostra o andamento da Pauta Mínima.

Como ocorreu no ano passado, a Agenda Legislativa foi mais propositiva e menos reativa em 2012 - ou seja, 59\% dos seus projetos convergem com as posições do setor, contra os restantes $41 \%$ contrários aos interesses da indústria.

Destaque-se ainda que neste ano manteve-se a tendência, registrada pela primeira vez em 2008, pela qual a maioria dos projetos de leis ordinárias se 
origina do próprio Congresso e não mais do governo. Câmara e Senado respondem por $67 \%$ deles, cabendo ao Executivo o envio de $20 \%$ (CNI, 2012, p. 13).

Por fim, a natureza pública tanto do posicionamento quanto da avaliação sobre sua relação com o Congresso Nacional faz parte dos padrões de ação política da CNI em relação ao parlamento, dado que não se trata de documentos internos ou restritos, mas, ao contrário, apresentados ao público em geral e às autoridades políticas. Voltaremos a essa questão mais adiante.

\section{O cotejamento entre as posições da CNI e o resultado do processo legislativo}

Como a análise aqui proposta se volta para a representação que a CNI constrói sobre sua relação com o Legislativo federal, a categoria convergência remete, mas não reproduz, a própria forma como essa entidade classifica as proposituras selecionadas pela $\mathrm{AL}^{23}$. Essa categoria tende a ser mais neutra em termos de estabelecimento de relações de causa e efeito e de inferências sobre força política.

Além disso, para o cotejamento que aqui propomos, adotamos outros critérios que se mostraram úteis para os nossos objetivos. Consideramos como convergência positiva quando o projeto avaliado como convergente com os interesses da CNI foi aprovado, e como convergência negativa quando o projeto avaliado como divergente foi arquivado, retirado pelo autor ou rejeitado. As proposituras que não se enquadram nessas duas condições foram classificadas como divergentes. Tais critérios reforçam a importância de enfatizar a classificação feita pela própria CNI das proposituras em relação aos seus interesses, aqui adaptada aos nossos objetivos.

A análise dos dados mostrou que entre 2010 e 2017 houve um total geral de 502 proposituras legislativas contempladas pela $A L$ da $C N I^{24}$. Destas, 359, ou seja, $71 \%$, eram consideradas convergentes, e 143 , ou seja, $29 \%$, eram vistas como divergentes em relação aos interesses da CNI. Dentre essas 502 proposições, 158, ou 31,5\% do total, foram finalizadas, ou seja, são decisões legislativas ${ }^{25}$. Destas, 96 , ou seja, $61 \%$, são proposituras em convergência com as posições da CNI, das quais 44, ou seja, 46\%, são casos de convergência positiva, portanto, eram classificadas como convergentes e foram

\footnotetext{
23 Ver item "O formato institucional da ação parlamentar da CNI" acima.

${ }^{24}$ Foram sistematizados 16 relatórios da CNI, que representam oito anos da agenda legislativa da indústria. Esse recorte metodológico se deu por conta de uma descontinuidade no formato dos relatórios, dado que a partir de 2010 eles passaram a conter informações mais complexas e um formato padronizado, o que não ocorria nos relatórios anteriores.

25 Tais proposições estão divididas entre: 55 novas normas jurídicas, que correspondem a $11 \%$ do total pesquisado e $34,8 \%$ das decisões legislativas; 91 proposituras arquivadas, que correspondem a $18 \%$ do total e $57,5 \%$ das decisões finalizadas; 4 proposituras rejeitadas, que correspondem a $0,8 \%$ do total; e 8 proposituras retiradas pelo autor, que correspondem a $1,6 \%$ do total. As demais 344 proposituras não foram finalizadas, representando $68,5 \%$ do total, as quais estão divididas entre 272 proposituras em tramitação, que correspondem a $54 \%$ do total geral, e 72 apensadas, que correspondem a $14,6 \%$ do total.
} 
transformadas em normas jurídicas. As outras 52, ou seja, 54\%, estavam em convergência negativa, ou seja, eram divergentes, mas foram arquivadas, retiradas pelo autor ou rejeitadas. Por fim, das 62 proposituras com divergência, que correspondem a 39\% das decisões legislativas, 11 eram divergentes e foram aprovadas e 51 eram convergentes, mas não foram aprovadas, ou seja, 47 foram arquivadas e 4 retiradas pelo autor.

Podemos perceber também que, das 55 novas normas jurídicas, 44 delas, ou seja, $80 \%$, estavam em convergência positiva e 11 delas, ou seja, $20 \%$, eram de divergência em relação às posições da CNI. E das 91 proposituras arquivadas, 44, portanto, 48,3\%, estavam em convergência negativa com a posição da CNI, contra 47, ou seja, 51,7\%, com divergência. Das 4 proposituras rejeitadas, todas eram divergentes com a posição da CNI. $\mathrm{E}$, das 8 que foram retiradas pelo autor, metade era convergente com a posição da CNI.

Quando consideramos a Pauta Mínima, das 502 proposituras do período, 66 foram contempladas, das quais 30 implicaram decisões legislativas. Destas, 17 estavam em convergência positiva (aprovadas) e 2, em convergência negativa (1 retirada e 1 arquivada) com a posição da CNI. Das 91 proposituras que foram arquivadas, verificamos que 9 delas faziam parte da Pauta Mínima e apenas 1 estava em convergência com a posição da CNI. Duas das 8 decisões legislativas que foram retiradas pelo autor faziam parte da Pauta Mínima, estando apenas 1 em convergência (negativa) com a posição da CNI. Nenhuma das proposituras rejeitadas estava na Pauta Mínima.

Ainda que não possamos aprofundar neste momento a análise do processo de construção da $A L$ no período aqui considerado, o tema mais frequente foi o interesse setorial, perfazendo um total de 142 projetos, ou seja, 28,3\% do total, de proposituras contempladas pela AL. Em segundo lugar, vem a legislação trabalhista, com 19,5\% do total dos projetos da $\mathrm{AL}$, seguida do sistema tributário e da regulamentação da economia (ver Gráfico 3). Além dos temas que mais chamam a atenção dos industriais quando se organizam para a ação no Legislativo através da CNI, esses dados indicam, de um lado, a forte presença dos interesses representados pelas associações nacionais setoriais de indústria, os quais desde 2001 compõem a AL e são resultado de um esforço da CNI em ampliar a representatividade da AL. E, de outro, mostram que a legislação trabalhista e o sistema tributário são os temas que mais unificam o empresariado industrial organizado em torno da CNI no período recortado. 
Gráfico 3

Temática das proposituras legislativas da AL da CNI (2010-2017)

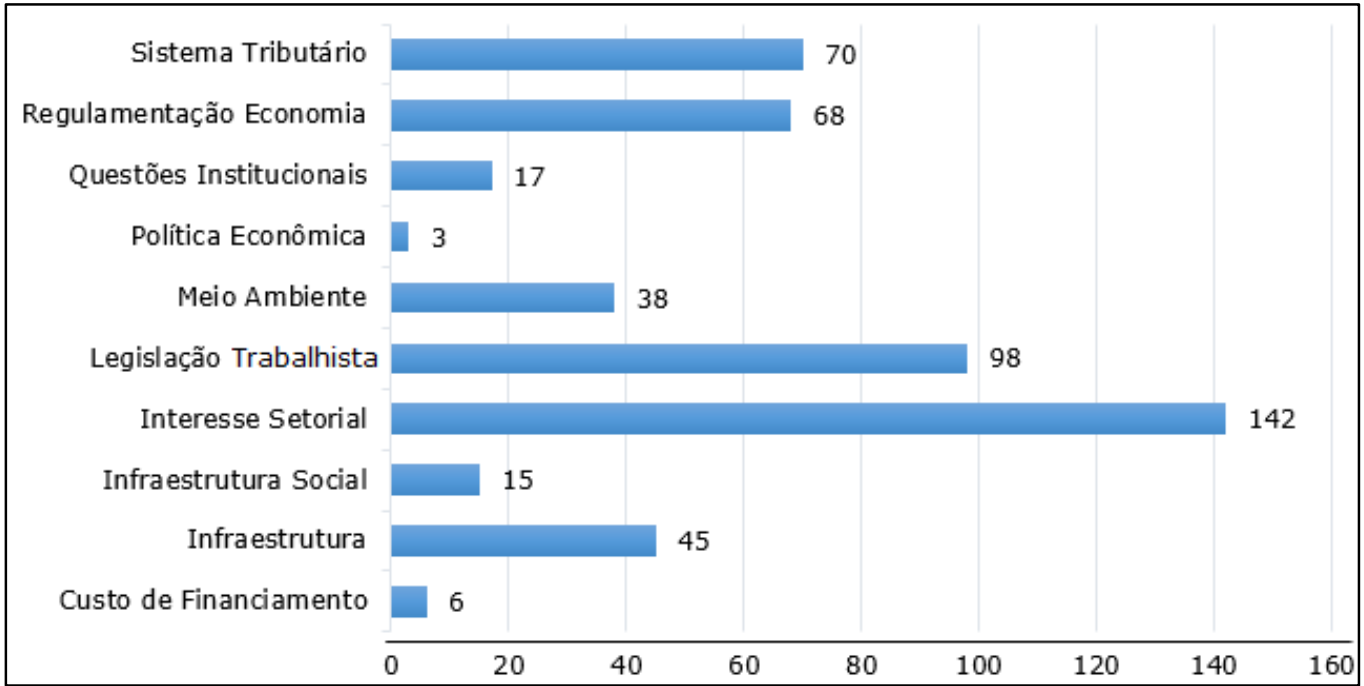

Fonte: Elaborado pelos autores a partir de dados da CNI.

Ainda em relação às 502 proposituras legislativas contempladas pela AL entre 2010 e 2017, verificamos que 266 foram de autoria da Câmara dos Deputados e outras 194 foram do Senado, contra 42 do Executivo Federal ${ }^{26}$. Do ponto de vista da CNI, a Câmara dos Deputados apresenta mais projetos que afetam de alguma forma a indústria nacional do que o Senado e o Poder Executivo juntos.

Mas, quando consideramos a convergência, verificamos que, das 266 proposições originadas na Câmara, 72 viraram decisão legislativa, estando 41 delas em convergência e 31 em divergência. Das 194 proposições oriundas do Senado, 55 viraram decisão legislativa, sendo que 35 estavam em convergência e 20 em divergência. Por sua vez, das 42 proposições vindas do Executivo no período, 31 viraram decisão legislativa, sendo que 20 estavam em convergência positiva e 11 em divergência com a posição da CNI. Ver Gráfico 4:

\footnotetext{
${ }^{26}$ Devemos destacar que essa distinção em relação à origem é adotada originalmente pela própria CNI no processamento dos projetos que tramitam no Legislativo.
} 


\section{Gráfico 4}

Total de proposituras que resultaram em decisões legislativas (2010-2017)

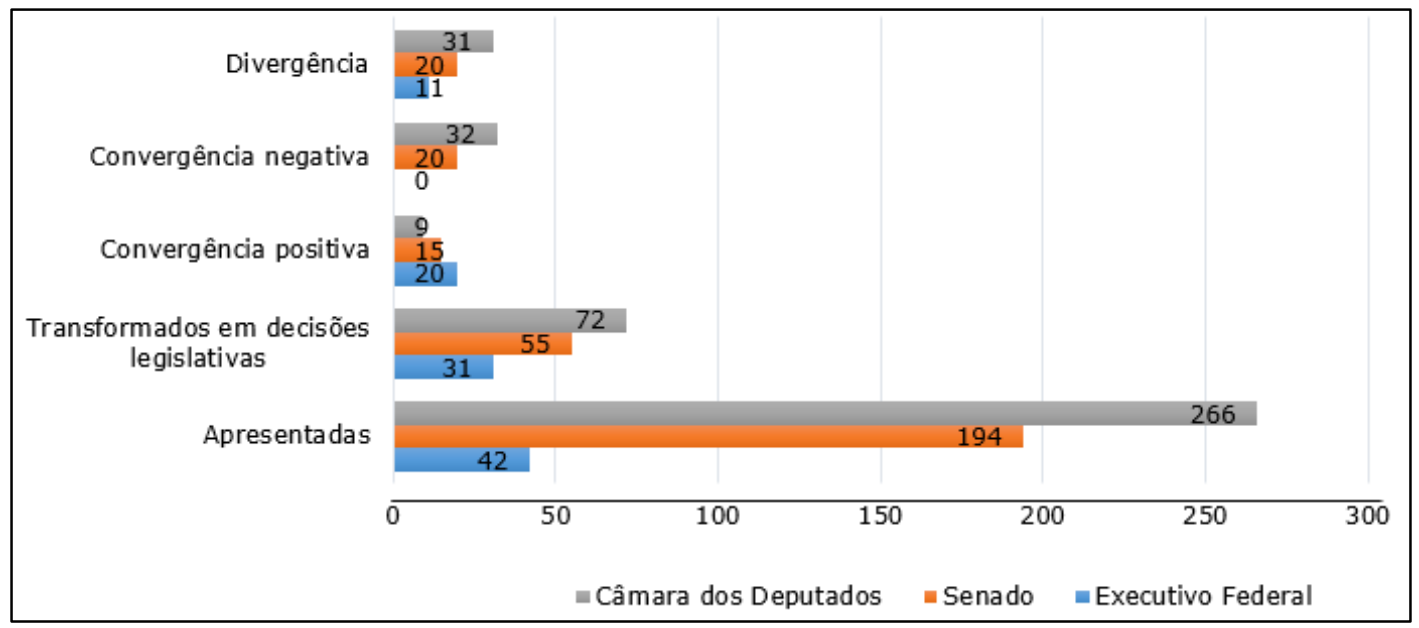

Fonte: Elaborado pelos autores a partir de dados da CNI.

Notamos, portanto, que, quando falamos de decisão legislativa, o Poder Executivo se mostra um autor com maior capacidade de obter convergência positiva com a posição da CNI do que a Câmara dos Deputados. No período estudado, o Poder Executivo, enquanto autor de proposituras, obteve 20 casos de convergência positiva, seguido do Senado com 15 casos e da Câmara dos Deputados, com 9 casos. Podemos também considerar a taxa de transformação em decisão legislativa (TDL), a taxa de convergência (TC) e a taxa de divergência (TD) de acordo com a origem das proposituras. Esses dados seguem na Tabela 1 e são representados no Gráfico 5 :

Tabela 1

Total de projetos analisados pela AL/Autoria das proposituras/Convergência (Positiva ou Negativa) e Divergência (2010-2017)

\begin{tabular}{|l|c|c|c|c|c|c|c|c|c|c|c|}
\hline & NP & DL & $\begin{array}{c}\text { TDL } \\
(\%)\end{array}$ & CP & $\begin{array}{c}\text { TCP } \\
(\%)\end{array}$ & CN & $\begin{array}{c}\text { TCN } \\
(\%)\end{array}$ & NTC & $\begin{array}{c}\text { TTC } \\
(\%)\end{array}$ & ND & $\begin{array}{c}\text { TD } \\
(\%)\end{array}$ \\
\hline $\begin{array}{l}\text { Câmara dos } \\
\text { Deputados }\end{array}$ & 266 & 72 & 27 & 9 & 3,38 & 32 & 12 & 41 & 15,4 & 31 & 11,6 \\
\hline Senado & 194 & 55 & 28,3 & 15 & 7,7 & 20 & 10,3 & 35 & 18 & 20 & 10,3 \\
\hline $\begin{array}{l}\text { Executivo } \\
\text { Federal }\end{array}$ & 42 & 31 & 73,8 & 20 & 47,6 & 0 & 0 & 20 & 47,6 & 11 & 26.1 \\
\hline Total & 502 & 158 & - & 44 & - & 52 & & 96 & - & 62 & \\
\hline
\end{tabular}

Fonte: CNI e Congresso Nacional.

Legenda: NP: número de projetos apresentados; DL: número de projetos transformados em decisões legislativas; TDL: taxa de decisão legislativa; CP: número de projetos em convergência positiva, considerando o número de projetos apresentados (NP); TCP: taxa de convergência positiva; CN: número de projetos em convergência negativa, considerando o número de projetos apresentados (NP); TCN: taxa de convergência negativa; NTC: soma de CP e CN; TTC: taxa total de convergência; ND: projetos em divergência; TD: taxa de divergência, considerando o número de projetos apresentados (NP). 
Gráfico 5

Taxa de convergência e divergência dividida por autoria - 2010-2017 (\%)

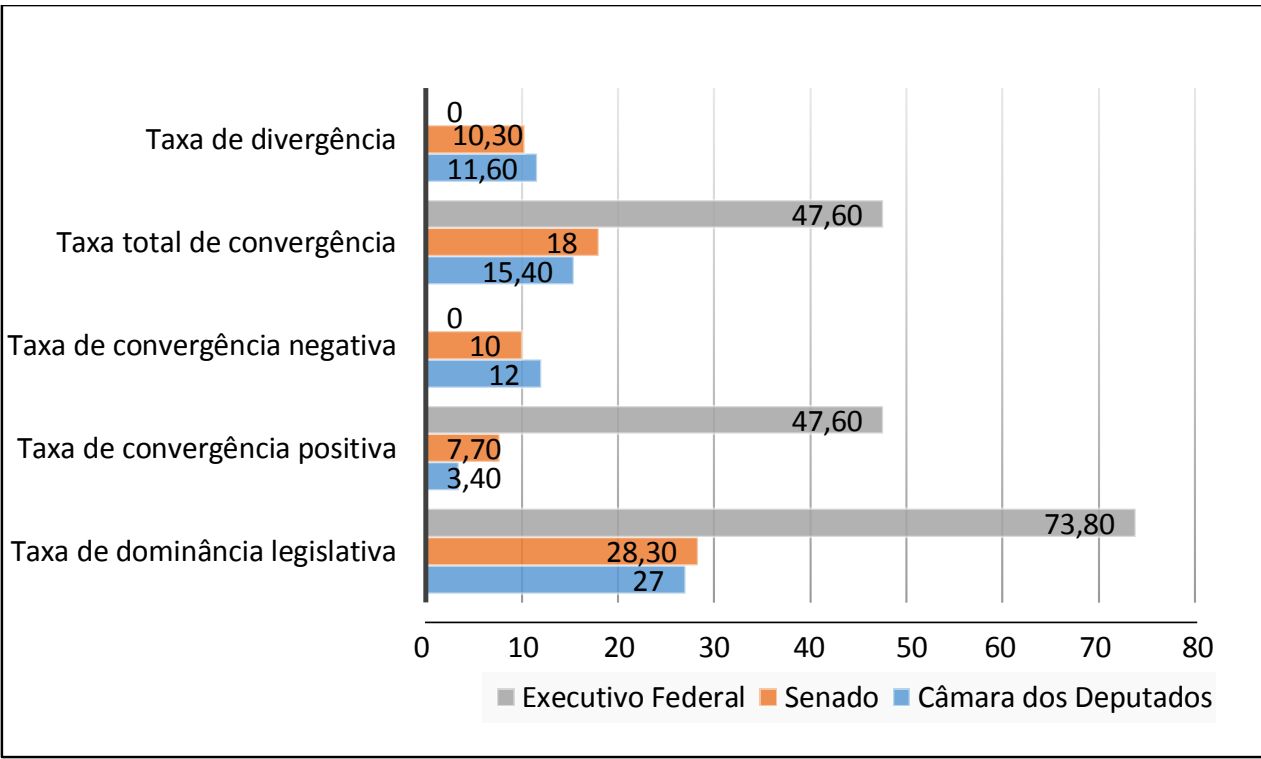

Fonte: Elaborado pelos autores a partir de dados da CNI.

Ainda sobre a origem das proposições, quando a consideramos por partidos políticos, verificamos que, das 44 proposições que foram finalizadas e que possuem convergência positiva, 8 foram de autoria do PMDB, 5 do PP, 3 do PSDB e 2 do PT. PDT, PFL (DEM), PMN, PR, PV e PSB possuem 1 propositura cada um. O Poder Executivo propôs 20 delas, superando os partidos. Mas, em relação à convergência negativa, o PMDB é o maior propositor com 12, seguido pelo PT com 8, o PSDB e o PFL (DEM) com 4 cada, o PDT e o PTB com 3 cada e o PP com 2 proposituras e PMN, PR, PSB e PV com 1 propositura cada. O poder Executivo não tem propositura com convergência negativa.

$\mathrm{E}$, quando consideramos as 62 proposituras com divergência, os maiores propositores são o Poder Executivo e o PT, com 11 cada, seguidos pelo PMDB, com 8, o PP e o PSB, com 5 cada, o DEM, com 4, o PSD, o PSDB e o PTB, com 3 cada e o PCdoB, o $\mathrm{PMN}$, O $\mathrm{PL}$, O PR e o SD, com 1 propositura cada27. Quanto à Pauta Mínima, verificamos que, das 17 proposituras com convergência positiva, 11 são do Executivo, 3 do PMDB, 2 do PSDB e 1 do PV; PT e DEM não têm proposituras com convergência positiva, mas têm uma convergência negativa cada.

\footnotetext{
27 As Comissões da Câmara têm 3 proposituras e as do Senado tem 1.
} 
Quando consideramos os dados relacionados à origem das proposituras por partidos políticos agregados por grupos no espectro ideológico ${ }^{28}$, os dados são sintetizados na Tabela 2:

Tabela 2

Total de projetos analisados pela AL/Autoria por partidos no espectro ideológico das proposituras/convergência (positiva ou negativa) e divergência

\begin{tabular}{|l|c|c|c|c|c|c|c|c|c|c|c|}
\hline & NP & DL & $\begin{array}{c}\text { TDL } \\
(\%)\end{array}$ & $\mathbf{C P}$ & $\begin{array}{c}\text { TCP } \\
(\mathbf{\%})\end{array}$ & $\mathbf{C N}$ & $\begin{array}{c}\text { TCN } \\
(\mathbf{\%})\end{array}$ & NTC & $\begin{array}{c}\text { TTC } \\
(\mathbf{\%})\end{array}$ & ND & $\begin{array}{c}\text { TD } \\
(\%)\end{array}$ \\
\hline Esquerda & 145 & 39 & 26.9 & 5 & 3,5 & 17 & 11,7 & 22 & 15,1 & 17 & 11,7 \\
\hline Centro & 92 & 34 & 36.9 & 8 & 8,6 & 15 & 16,3 & 23 & 25 & 11 & 11,9 \\
\hline Direita & 208 & 48 & 23,1 & 11 & 5,2 & 18 & 8,6 & 29 & 13,9 & 19 & 9,1 \\
\hline Total & $445^{*}$ & 121 & - & 24 & - & 50 & - & & - & 47 & - \\
\hline
\end{tabular}

Fonte: CNI e Congresso Nacional.

Legenda: NP: número de projetos apresentados; DL: número de projetos transformados em decisões legislativas; TDL: taxa de decisão legislativa; CP: número de projetos em convergência positiva, considerando o número de projetos apresentados (NP); TCP: taxa de convergência positiva; CN: número de projetos em convergência negativa, considerando o número de projetos apresentados (NP); TCN: taxa de convergência negativa; NTC: soma de CP e CN; TTC: taxa total de convergência; ND: projetos em divergência; TD: taxa de divergência, considerando o número de projetos apresentados (NP).

(*) O total de proposituras legislativas foi diminuído de 502 para 445 porque foram excluídas da análise 42 proposições legislativas de autoria do Poder Executivo e 15 das comissões do Senado e da Câmara dos Deputados.

Verificamos que os partidos de direita foram os que mais ocuparam a AL com quase metade das proposituras oriundas dos partidos e mais de $40 \%$ dos 502 projetos contemplados pela $\mathrm{AL}$, incluindo os projetos vindos do Executivo e das comissões, e mais de $46 \%$ quando consideradas apenas as 445 proposições dos partidos. Entretanto, embora tenha sido o segmento que teve menor taxa de proposições finalizadas, obteve mais convergência negativa do que positiva, ficando com a mais baixa taxa total de convergência (TTC). Em relação ao centro, por um lado, embora seja o que menos esteve presente na $A L$, tem a mais alta taxa de decisão legislativa (TDL). Por outro lado, tem duas vezes mais convergência negativa do que positiva, e mais convergência negativa do que a esquerda. Ver Gráfico 6:

\footnotetext{
28 Estamos considerando a escala de Krause, Rebello e Silva (2015), que estabelece a seguinte distribuição: Centro: PMDB e PSDB; Direita: PAN, PEN, PFL/DEM, PGT, PHS, PL/PR, PMN, PPB/PP, PPL, PRB, PRN, PRONA, PROS, PRP, PRTB, PSC, PSDB, PSDC, PSL, PST, PTdoB, PTB, PTC, PTN, SD; Esquerda: PT, PCdoB, PDT, PHS, PPS, PSB, PSOL e PV. O PSDB, segundo a classificação desses estudos, passou do centro para a direita nas eleições de 2014, e o PHS, da esquerda para a direita a partir das eleições de 2010 .
} 


\section{Gráfico 6 \\ Número total de projetos em convergência ou divergência divididos por espectro ideológico (2010-2017)}

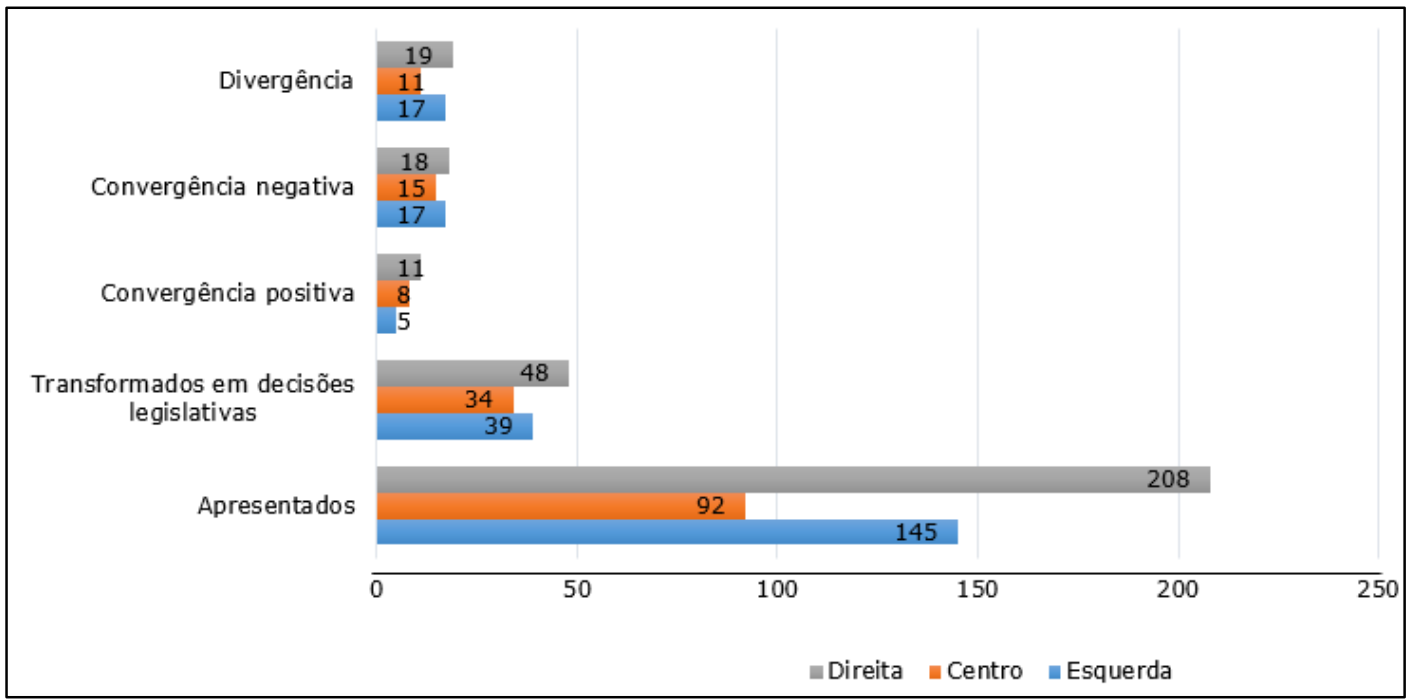

Fonte: Elaborado pelos autores a partir de dados da CNI.

Por último, outra forma de cotejamento que podemos explorar é a relação entre as posições da CNI e os partidos distribuídos entre governo e oposição, agora considerando as proposições que foram finalizadas, dado que nos interessa destacar a relação da CNI com os resultados efetivos do processo legislativo (ver Gráfico 7). Deve-se levar em conta que o período aqui contemplado remete a praticamente ao segundo mandato de Lula da Silva e o primeiro de Dilma Rousseff, o que limita a possibilidade de comparação com outros governos ${ }^{29}$. Em primeiro lugar, considerando a $53^{\text {a }}$ Legislatura do Congresso Nacional, mais especificamente o ano de $2010^{30}$, como indica a Tabela 3, observamos que os partidos da base parlamentar do governo têm uma maior taxa de decisão legislativa (TDL) do que os da oposição ${ }^{31}$. Além disso verificamos que a taxa total de convergência (TTC) dos partidos de governo é de $51,6 \%$, enquanto a oposição não existe, porque nesse ano ela não apresentou proposições em convergência, positiva ou negativa, mas apenas em divergência com a CNI.

\footnotetext{
29 Apesar de nossa pesquisa abranger o período até 2017 , as proposições contempladas pela CNI remetiam ao período anterior ao início do governo de Michel Temer, quando a base partidária do governo sofreu alterações importantes.

${ }^{30}$ Esse recorte se deve ao fato de que esse é o último ano dessa legislatura e por estarmos considerando a AL de 2010. Como vimos acima, a AL possui um caráter cumulativo dos anos anteriores, dado que alguns dos projetos contemplados tiveram início em momentos anteriores.

${ }^{31}$ Enquanto partidos do governo, consideramos as seguintes legendas: PT, PMDB, PRB, PCdoB, PSB, PP, PR, PTB, PV, PDT, PAN, PSC, PTdoB, PMN e PHS. Os partidos de oposição seriam: PSDB, DEM, PSOL e PPS (Bezerra, 2012). Na análise desse período consideramos a AL dos anos de 2011 a 2014.
} 


\section{Gráfico 7}

Taxa de convergência e divergência dividida por partidos de governo e oposição $53^{\text {a }}$ legislatura do Congresso Nacional (\%)

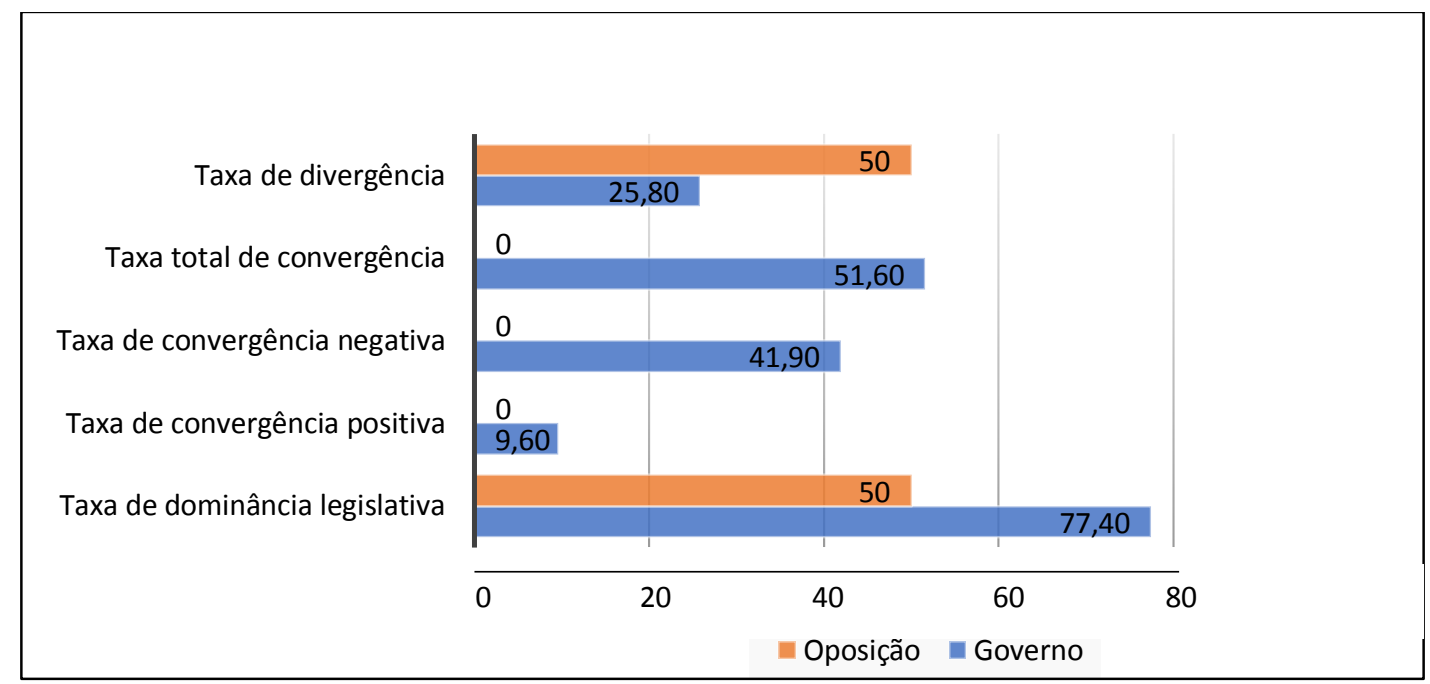

Fonte: Elaborado pelos autores a partir de dados da CNI.

Entretanto, os partidos do governo produziram mais convergência negativa do que positiva. Notamos também que esses partidos produziram $25,8 \%$ de divergência e que, apesar do baixo número de proposições dos partidos de oposição, eles tiveram $50 \%$ de divergência. Ver Tabela 3:

Tabela 3

Total de projetos analisados pela AL*/partidos políticos - governo/oposição $53^{a}$ Legislatura do Congresso Nacional (governo Lula, 2010)/convergência (positiva ou negativa) ou divergência**

\begin{tabular}{|l|c|c|c|c|c|c|c|c|c|c|c|}
\hline & NP & DL & $\begin{array}{c}\text { TDL } \\
(\%)\end{array}$ & CP & $\begin{array}{c}\text { TCP } \\
(\%)\end{array}$ & CN & $\begin{array}{c}\text { TCN } \\
(\%)\end{array}$ & NTC & $\begin{array}{c}\text { TTC } \\
(\%)\end{array}$ & ND & $\begin{array}{c}\text { TD } \\
(\%)\end{array}$ \\
\hline Governo & 31 & 24 & 77,4 & 3 & 9,6 & 13 & 41,9 & 16 & 51,6 & 8 & 25,8 \\
\hline Oposição & 6 & 3 & 50 & 0 & 0 & 0 & 0 & 0 & 0 & 3 & 50 \\
\hline Total & 37 & 27 & - & 3 & - & 13 & - & 16 & - & 11 & - \\
\hline
\end{tabular}

Fonte: CNI e Congresso Nacional.

Legenda: NP: número de projetos apresentados; DL: número de projetos transformados em decisões legislativas; TDL: taxa de decisão legislativa; CP: número de projetos em convergência positiva, considerando os projetos transformados em decisões legislativas; TCP: taxa de convergência positiva; CN: número de projetos em convergência negativa, considerando os projetos transformados em decisões legislativas; TCN: taxa de convergência negativa; NTC: soma de CP e CN; TTC: taxa total de convergência; ND: projetos em divergência; TD: taxa de divergência, considerando as decisões legislativas (DL).

* O total de proposituras legislativas foi diminuído de 502, para 445, porque excluímos da análise as 37 decisões legislativas de autoria do Poder Executivo e das comissões do Senado e da Câmara.

** Os cálculos relacionados a convergência e divergência foram feitos a partir do número de proposições que viraram decisões legislativas (DL). 
Considerando a 54ª Legislatura do Congresso Nacional (de 2011 a 2014), período do governo de Dilma Rousseff, a divisão entre partidos do governo e partidos da oposição não sofre alterações ${ }^{32}$. Os dados apresentados na Tabela 4, relativos à AL de 2014, mostram que, embora os partidos do governo tenham aumentado o número de proposições e mantido a maior taxa de decisão legislativa, perderam em convergência positiva e aumentaram em convergência negativa, enquanto a oposição cresceu em relação ao total de proposituras legislativas apresentadas e finalizadas. Comparando com a legislatura anterior, as taxas de convergência positiva e negativa de governo e oposição estão mais equilibradas, o mesmo ocorrendo em relação à taxa de divergência. Ver Tabela 4 e Gráfico 8:

\section{Tabela 4}

Total de projetos analisados pela AL*/partidos políticos - governo/oposição $5_{4}^{a}$ Legislatura do Congresso Nacional (Dilma Rousseff, 2011-2014)/convergência (positiva ou negativa) ou divergência**

\begin{tabular}{|l|c|c|c|c|c|c|c|c|c|c|c|}
\hline & NP & DL & $\begin{array}{c}\text { TDL } \\
(\%)\end{array}$ & $\mathbf{C P}$ & $\begin{array}{c}\text { TCP } \\
(\%)\end{array}$ & $\mathbf{C N}$ & $\begin{array}{c}\text { TCN } \\
(\%)\end{array}$ & NTC & $\begin{array}{c}\text { TTC } \\
(\%)\end{array}$ & ND & $\begin{array}{c}\text { TD } \\
(\%)\end{array}$ \\
\hline Governo & 143 & 61 & 42,6 & 9 & 6,2 & 24 & 16,7 & 33 & 23 & 28 & 19,5 \\
\hline Oposição & 41 & 15 & 36,5 & 2 & 4,8 & 8 & 19,5 & 10 & 24,3 & 5 & 12,1 \\
\hline Total & 184 & 76 & - & 11 & - & 32 & - & 56 & - & 33 & - \\
\hline
\end{tabular}

Fonte: CNI e Congresso Nacional.

Legenda: NP: número de projetos apresentados; DL: número de projetos transformados em decisões legislativas; TDL: taxa de decisão legislativa; CP: número de projetos em convergência positiva, considerando os projetos transformados em decisões legislativas; TCP: taxa de convergência Positiva; CN: número de projetos em convergência negativa, considerando os projetos transformados em decisões legislativas; TCN: taxa de convergência negativa; NTC: soma de CP e CN; TTC: taxa total de convergência; ND: projetos em divergência; TD: taxa de divergência, considerando as decisões legislativas (DL).

* O total de proposituras legislativas foi diminuído de 502, para 445, porque excluímos da análise as 37 decisões legislativas de autoria do Poder Executivo e das comissões do Senado e da Câmara.

** Os cálculos relacionados a convergência e divergência foram feitos a partir do número de proposições que viraram decisões legislativas $(\mathrm{DL})$.

\footnotetext{
32 A partir de levantamento do Departamento Intersindical de Assessoria Parlamentar (Diap, 2014), estamos considerando como partidos de governo PT, PMDB, PRB, PCdoB, PSB, PP, PR, PTB, PV, PDT, PAN, PSC, PTdoB, PMN e PHS, e de oposição PSDB, DEM, PSOL e PPS.
} 


\section{Gráfico 8}

Taxa de convergência e divergência dividida por partidos de governo e oposição $54^{a}$ legislatura do Congresso Nacional (\%)

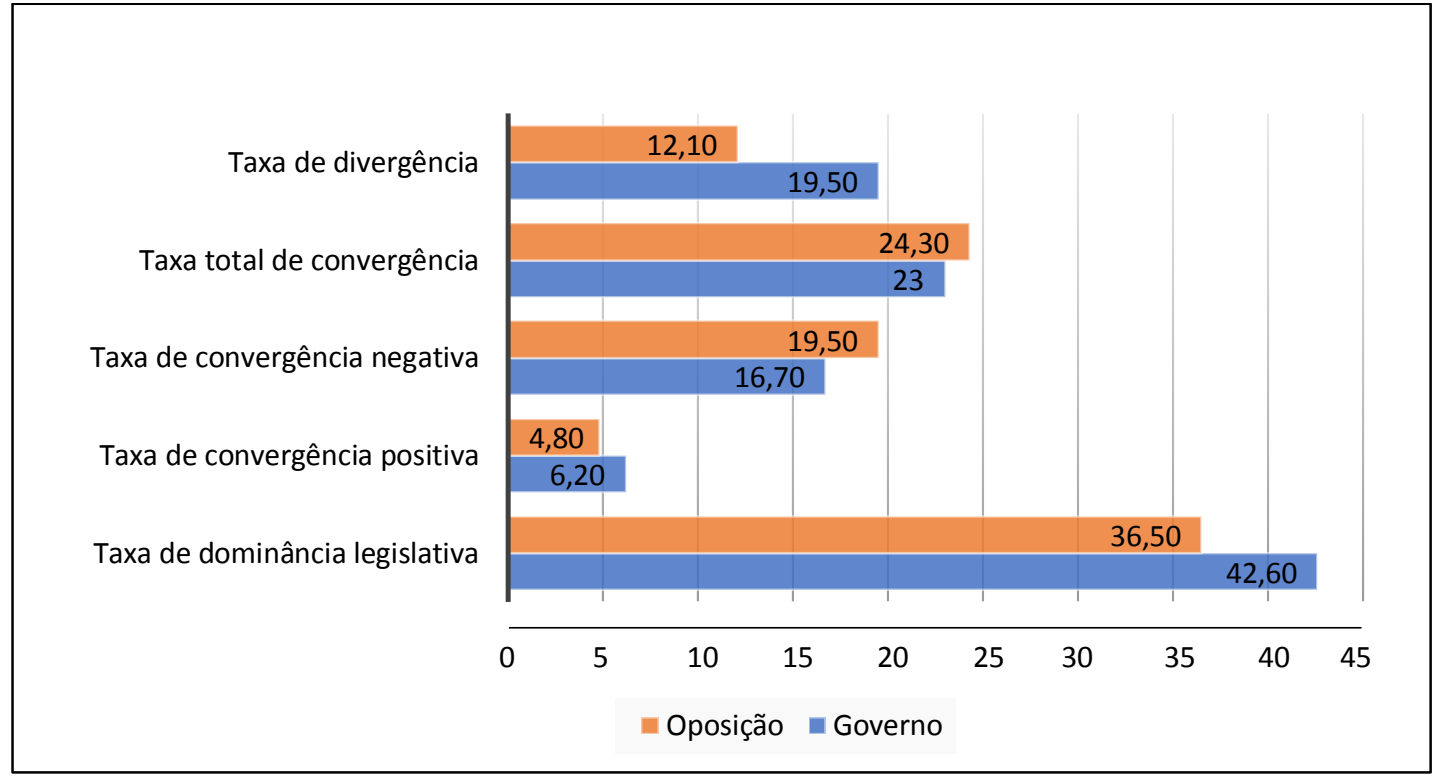

Fonte: Elaborado pelos autores a partir de dados da CNI.

Por fim, quando consideramos a 55a Legislatura do Congresso Nacional, correspondendo ao governo de Dilma Rousseff de 2015 até seu afastamento em 2016, constatamos que a principal mudança é no número de proposições que tiveram decisão legislativa ${ }^{33}$.

33 Nessa análise, consideramos as ALs de 2015 e 2016. 


\section{Tabela 5}

Total de projetos analisados pela AL*/partidos políticos - governo/oposição $55^{\text {a }}$ Legislatura do Congresso Nacional (Dilma Rousseff, 2015-2016)/convergência (positiva ou negativa) ou divergência**

\begin{tabular}{|l|c|c|c|c|c|c|c|c|c|c|c|}
\hline & NP & DL & $\begin{array}{c}\text { TSL } \\
(\mathbf{\%})\end{array}$ & $\mathbf{C P}$ & $\begin{array}{c}\text { TCP } \\
(\mathbf{\%})\end{array}$ & $\mathbf{C N}$ & $\begin{array}{c}\text { TCN } \\
(\mathbf{\%})\end{array}$ & $\mathbf{N T C}$ & $\begin{array}{c}\text { TTC } \\
(\mathbf{\%})\end{array}$ & ND & $\begin{array}{c}\text { TD } \\
(\mathbf{\%})\end{array}$ \\
\hline Governo & 148 & 15 & 10,1 & 8 & 5,4 & 3 & 2,2 & 11 & 7,4 & 4 & 2,7 \\
\hline Oposição & 28 & 3 & 10,7 & 2 & 7,1 & 1 & 3,6 & 3 & 10,7 & 0 & 0 \\
\hline Total & 176 & 18 & - & 10 & - & 4 & - & 14 & - & 4 & - \\
\hline
\end{tabular}

Fontes: CNI e Congresso Nacional.

Legenda: NP: número de projetos apresentados; DL: número de projetos transformados em decisões legislativas; TDL: taxa de decisão legislativa; CP: número de projetos em convergência positiva, considerando os projetos transformados em decisões legislativas; TCP: taxa de convergência positiva; CN: número de projetos em convergência negativa, considerando os projetos transformados em decisões legislativas; TCN: taxa de convergência negativa; NTC: soma de CP e CN; TTC: taxa total de convergência; ND: projetos em divergência; TD: taxa de divergência, considerando as decisões legislativas (DL).

* O total de proposituras legislativas foi diminuído de 502, para 445, porque excluímos da análise as 37 decisões legislativas de autoria do Poder Executivo e das comissões do Senado e da Câmara.

** Os cálculos relacionados a convergência e divergência foram feitos a partir do número de proposições que viraram decisões legislativas (DL).

\section{A análise da relação entre a CNI e o Congresso Nacional}

Nesta seção, analisamos os dados apresentados a partir de nossas categorias analíticas. Como vimos acima, a sociologia política do Poder Legislativo aqui proposta se dá, em primeiro lugar, através da análise da relação entre uma importante entidade de representação empresarial e o Congresso Nacional, permitindo a verificação dos condicionantes institucionais - no caso, internos à entidade - ou seja, o formato institucional adotado por ela para a construção de sua ação. Em segundo lugar, ela considera a avaliação e a caracterização, ou seja, a representação que esse grupo faz dessa relação. $E$, em terceiro lugar, analisa a convergência entre suas posições e o processo legislativo. Desse modo, propusemos acima: uma análise que articula o processo institucional de constituição de um dado coletivo, no caso, os empresários industriais, enquanto ator político; a forma como ele próprio vê sua relação com a política, no caso, o processo legislativo; e, por fim, a verificação dos resultados dessa ação.

\section{A análise do formato institucional}

A análise do formato institucional permitiu verificar as particularidades da forma do envolvimento efetivo da CNI com o processo legislativo federal e indicou também uma forma específica da relação entre dinheiro ou recursos financeiros, no caso, de uma entidade sindical de terceiro grau, e a política. Verificamos que existe uma complexa estrutura de órgãos e técnicos envolvidos no processo que vai da análise das proposituras, 
passando pela definição e a divulgação da posição da entidade, até a atuação efetiva e a avaliação dos resultados.

Enfim, os recursos financeiros, técnicos e materiais que essa entidade possui se mostraram decisivos para o seu protagonismo político no Legislativo, ou seja, permitiram à entidade constituir uma estrutura organizacional e um corpo técnico complexo, o qual pode ser mantido até mesmo sem as formas compulsórias de arrecadação que lhe marcaram a origem e a história. Tal aspecto merece maior atenção e um estudo mais aprofundado, mas remete a uma das características do processo de constituição das formas institucionais de representação do empresariado e de seu estágio atual nas sociedades capitalistas em geral e no Brasil em particular. A estrutura institucional da CNI para o acompanhamento do processo legislativo não foi aqui analisada em todas as suas frentes ${ }^{34}$. Mas isso não compromete a perspectiva aqui proposta de verificar o ponto de vista do próprio agente na descrição e avaliação de seus procedimentos institucionais internos.

Apenas como exemplo de questão que não pode ser aqui desenvolvida, a análise do caso da AL da CNI e, em particular, da forma como ela é produzida através do Seminário RedIndústria remete ao debate sobre a questão das entidades de cúpula no âmbito empresarial ${ }^{35}$. Observamos que a CNI parece realizar esse papel através da forma institucional como congrega e dá suporte à representação de diversos interesses setoriais da indústria, ao menos em relação ao Congresso Nacional, inclusive administrando os conflitos de interesse e promovendo a integração desses setores no processo político a partir de um processo de natureza deliberativa, no qual os atores também aprendem tanto a defender seus interesses quanto a articulá-los em um processo que envolve as disputas e conflitos internos e a preparação para a ação externa.

Entretanto, observamos que há um certo descompasso entre o volume de proposituras contempladas pela $\mathrm{AL}$ e $\mathrm{o}$ número daquelas que recebem um acompanhamento por parte da entidade. Poucos projetos parecem ser de fato monitorados e sujeitos a uma estratégia de atuação, e, certamente, isso está sujeito à correlação de forças no interior da entidade e às particularidades das demandas e interesses setoriais.

Em suma, os aspectos institucionais contam, mas sobretudo naquilo que revelam do complexo processo de constituição dos industriais enquanto atores políticos através da CNI, no caso, na arena legislativa.

\footnotetext{
34 Nosso objetivo não foi contemplar em toda a sua complexidade os procedimentos que caracterizam o formato institucional da atuação parlamentar da CNI, como o Legisdata e o aplicativo disponibilizado para o acompanhamento do processo legislativo, através do qual se podem obter dados e fazer pesquisas específicas voltadas para a atuação e a defesa de interesses específicos no Congresso Nacional. Sobre isso, ver: <http://www.portaldaindustria.com.br/agenciacni/noticias/2017/03/cni-lanca-aplicativo-da-agendalegislativa-da-industria-para-ios-e-android/>. Acesso em: 12 nov. 2017.

35 Sobre essa questão nos estudos sobre o empresariado, ver o trabalho de Schneider (2004) e de Diniz e Boschi (Szwako, Moura e D'Avila Filho, 2016).
} 


\section{A análise da representação}

Quando consideramos a representação da CNI quanto à sua relação com o Legislativo federal, estamos propondo que a maneira como um ator social caracteriza e avalia sua relação com as instituições políticas é uma forma privilegiada de verificar o grau de adesão e envolvimento com tais instituições e com o arranjo ao qual pertencem, ou seja, o regime político. Portanto, é uma ferramenta analítica interessante para compreender as particularidades da relação entre esse ator e aquelas instituições e verificar o quanto e de que forma ele se constitui como uma de suas bases sociais.

Constatamos a importância que a entidade dá para esse âmbito de suas frentes de atuação. Isso pode ser comprovado pela estrutura e pelo formato institucional que a entidade constitui para tratar dessa frente, inclusive pelos órgãos internos relacionados à $A L$, e pela qualificação da equipe de técnicos envolvida. Além disso, como vimos acima, faz parte desse processo a tentativa de agregar outras entidades, sindicais e associativas, de diversos segmentos, chamados de "interesses setoriais", e regiões do país. Por fim, a natureza pública que é dada aos documentos produzidos também sinaliza a valorização da divulgação de suas posições e do debate sobre o Congresso Nacional, ou seja, a importância que dá para as suas próprias posições e o entendimento de que é melhor torná-las públicas, o que não nos permite a ingenuidade de pensar que tudo vem a público, como é natural no jogo político nas democracias.

Além disso, a análise da representação indica o alto grau de satisfação com a instituição Congresso Nacional e com os resultados que essa instituição produz em relação ao que a CNI considera serem os interesses da indústria. Há também um sentimento de conhecimento e compreensão do processo legislativo em seus diversos âmbitos, como sugere a forma como a CNI se refere à sua atuação nas comissões.

Quando comparamos a avaliação positiva da CNI - que, como vimos, se refere tanto ao Congresso Nacional enquanto instituição quanto aos resultados do processo legislativo em relação àquilo que estabeleceu como seus interesses - com a análise da convergência, verificamos que há uma proximidade entre os resultados e o diagnóstico sobre estes, apesar da tendência a deixar em segundo plano o relevante grau de divergência e a considerar como bem-sucedidas as propostas divergentes que ainda não haviam sido finalizadas.

Seja como for, essa avaliação positiva não significa uma plena satisfação, o que nos parece natural, mas sugere a hipótese de que há uma consciência por parte da CNI de que isso não seria realista e de que o "equilíbrio" entre resultados positivos e negativos é o que se pode considerar satisfatório. Isso indica um alto grau de satisfação com a instituição Congresso Nacional, corroborando achados de outras pesquisas (Costa, 2012).

Em suma, a CNI vê a si própria e os industriais como atores políticos fortes e eficazes e o Congresso Nacional como um espaço político importante e favorável aos seus interesses. Não se trata de aceitar, concordar ou discordar de tal diagnóstico, mas sim de 
considerá-lo como parte do processo de constituição e efetivação dos industriais enquanto atores políticos e das suas relações com as instituições políticas. Nesse sentido, entendemos que a verificação sociológica da força política de um dado ator passa pela verificação da representação que ele faz sobre si próprio e sobre o espaço institucional da sua luta política, dado o impacto que isso tem nas suas estratégias de ação e nas suas relações com as instituições. Assim, o próprio ator está satisfeito com o funcionamento da instituição - no caso, o Legislativo, ao qual estão relacionadas outras instituições igualmente fundamentais da democracia, que são o Poder Executivo, os partidos políticos e as eleições -, e o fato de isso ter acontecido em função de sua atuação direta e do eventual sucesso é muito importante, mas não é a única dimensão relevante na análise da sua relação com tal instituição.

Wagner Mancuso já chamava a atenção para a importância de recorrer a critérios internos ao empresariado industrial e para a sua relevância na construção de estratégias mais eficazes de análise da ação desse grupo, embora sua preocupação fosse mais especificamente com a questão da "tese da debilidade" do grupo que a literatura tendeu a chamar de burguesia industrial (Mancuso, 2004, 2007a). Aqui buscamos analisar a construção de seus interesses como parte do processo de sua constituição enquanto ator político na luta parlamentar e a forma como esse próprio ator avalia o resultado desse processo. Constatamos que a CNI se vê como um ator bem-sucedido, ficando a questão da verificação de sua força e dos seus padrões de ação política para outra abordagem, como veremos mais adiante.

\section{A análise do cotejamento}

Quando consideramos o cotejamento entre a convergência das posições da CNI e os resultados do processo legislativo, destaca-se o grande número de projetos contemplados pela AL. Os 502 projetos contêm proposituras que, embora iniciadas há vários anos, ainda estavam ativas no Congresso Nacional, ao lado de projetos mais recentes. Outro aspecto importante é que todos os projetos contemplados se referem de fato a interesses da indústria e não se relacionam a assuntos genéricos.

Assim, a CNI parece aceitar com naturalidade o fato de que mais de dois terços das matérias analisadas pela AL não tenham sido resolvidas, independentemente dos resultados, dado que isso não aparece na sua representação sobre a sua relação com o Congresso Nacional. O que sugere a hipótese de uma aceitação da morosidade e da complexidade do processo legislativo, além do fato de que interessa à entidade a não finalização das proposituras em divergência com seus interesses e de que, de certa forma, poderiam ser consideradas como um resultado positivo, ainda que não definitivo ${ }^{36}$.

\footnotetext{
36 Os projetos analisados pela AL tramitam numa escala temporal que varia de 1991 até 2016 . A CNI se posicionou como divergente ou divergente com ressalvas ante 143 dos 502 projetos contemplados pela AL. Desses 143 projetos, 37 foram apensados a outros projetos e 106 ainda estão em tramitação regular.
} 
Além disso, verificamos que, por um lado, mais de $71 \%$ das proposições analisadas e quase dois terços das que viraram decisões legislativas tiveram convergência com a posição da CNI, o que confirma, por outro método, o diagnóstico otimista e favorável expresso na representação que a entidade faz da sua relação com o Congresso Nacional, tanto no que tange à importância desse poder para seus interesses quanto para o seu desempenho nele. Por outro lado, houve certo equilíbrio entre a convergência positiva e a convergência negativa e entre estas e a divergência. Por outras vias, esses dados reforçam a representação da CNI de que os resultados do processo legislativo lhe são predominantemente favoráveis, e que isso pode se dar tanto na aprovação quanto na não aprovação dos projetos.

Devemos considerar que a avaliação da CNI se dá pela votação de cada parlamentar, ou seja, eles englobam em suas análises projetos finalizados (decisão legislativa) e não finalizados (em tramitação ou apensados), porque o que a entidade considera é a quantia de votos que a indústria teve por ano a favor de seus interesses e a quantia de votos contra seus interesses. Assim, são contabilizados como bem-sucedidos ou convergentes com os interesses da entidade os projetos que avançam em sua tramitação de uma comissão para outra, por exemplo, mesmo não tendo sofrido decisão legislativa final. $\mathrm{E}$, de cada cinco das proposições que viraram norma jurídica, quatro tinham convergência com a posição da CNI.

Por sua vez, a divergência indica que muitos projetos convergentes não foram aprovados, o que certamente deveria entrar na contabilidade da entidade quando avalia o resultado do processo legislativo, embora represente pouco mais de $10 \%$ do total de projetos contemplados pela $\mathrm{AL}$ no período e quase metade do número de decisões legislativas com convergência.

Quando olhamos para aquilo que foi contemplado pela Pauta Mínima, e que seria a seleção das questões consideradas prioritárias e mais importantes pela CNI, a maior parte das proposituras viraram decisões legislativas, das quais dois terços tinham convergência com a posição da CNI. Assim, manteve-se a taxa de convergência verificada no total dos projetos que viraram decisões legislativas. Enfim, embora o fato de um projeto estar na Pauta Mínima não signifique que haverá mais chance de convergência, a avaliação positiva por parte da CNI em relação a tais proposituras ocorre da mesma forma.

$\mathrm{E}$, em relação à convergência, o alto número de projetos que se caracterizam por não decisões legislativas sugere duas possibilidades: 1- a de verificar o grau de convergência que no futuro venha a acontecer com essas proposituras; 2- que estaria ocorrendo uma convergência negativa, ou seja, que as proposituras consideradas divergentes ao menos não foram aprovadas. Esses são exemplos de hipóteses de trabalho surgidas neste artigo, as quais serão retomadas mais adiante.

Por último, outros aspectos podem ser destacados a partir do cotejamento entre as posições da CNI e os resultados do processo legislativo. Ao considerarmos a origem das proposições, como mostra a Tabela 1, embora a Câmara seja a instância com maior 
número das proposições presentes na $A L$, seguida do Senado e do Poder Executivo, essa relação se inverte quando consideramos tanto o resultado em termos de transformação das propostas em decisão legislativa quanto a convergência com a posição da CNI. Por sinal, como vimos, o Executivo é o único autor que não tem proposituras em convergência negativa e o que mais tem convergência positiva, o que nos permite especular a hipótese de que, no âmbito do Executivo, existem mais possibilidades de acertos prévios e interferência da entidade do que nas casas do Legislativo, cuja comprovação exigiria novos estudos, lembrando que a CNI possui também uma assessoria específica para suas relações com o Poder Executivo ${ }^{37}$. Assim, o que vem do Executivo chama muito mais a atenção da CNI, seja pelo número de proposições que são finalizadas (aprovadas, rejeitadas ou arquivadas), seja pela alta taxa de convergência positiva e pela ausência de convergência negativa e mesmo pela relevante taxa de divergência.

Portanto, os dados indicam que o Executivo possui altas taxas de sucesso e de dominância quando consideramos os projetos contidos na AL da CNI no período aqui contemplado ${ }^{38}$. Mas nossos dados indicam outro aspecto interessante, ou seja, dois terços do que foi proposto pelo Executivo e que convergia com os interesses da CNI viraram decisões legislativas. Isso permite tratar da governabilidade do Poder Executivo pelo ponto de vista desse setor do empresariado. Ainda que essa questão mereça outros desdobramentos analíticos, indica uma aproximação entre empresariado, Executivo e Legislativo, ainda que em relação a este último haja muito mais divergência e correspondência negativa.

Quando consideramos a origem dos projetos por partidos políticos, podemos notar que a existência de convergência positiva não implica ausência de convergência negativa ou mesmo de divergência, o que indica que não há uma relação consistente, positiva ou negativa, entre os interesses defendidos pela CNI e este ou aquele partido. Mesmo que haja certa tendência de as propostas do PT terem menor número de convergência negativa ou divergência do que convergência positiva, os dados não indicam uma situação muito diferente em relação ao PMDB e mesmo a outros partidos políticos.

$E$, quando consideramos a relação entre convergência e autoria de partidos agregados em posições no espectro ideológico, levando em conta que não necessariamente se trata de grupos que se articulam de forma programática ou parlamentar, verificamos que, mesmo que haja certa predominância daquilo que vem dos partidos de direita e uma maior rejeição do segmento de esquerda, os dados sugerem que há certa dispersão na relação entre a produção legislativa dos partidos no espectro ideológico, o que indica que não há relações fortes entre posição ideológica dos partidos e posição política da CNI.

\footnotetext{
37 Sobre a relação entre interesses empresariais, Legislativo e Executivo, ver Santos et al. (2015).

38 Argelina Figueiredo e Fernando Limongi não apenas constatam a ocorrência dessas taxas em relação à produção legislativa em geral, como disso inferem, entre outros aspectos, a governabilidade que vem marcando o funcionamento de nossa democracia desde 1988 (Figueiredo e Limongi, 1999, 2012, 2017).
} 
Além disso, por um lado, a maior convergência com as proposições dos partidos de direita e de centro ocorre como convergência tanto positiva quanto negativa ${ }^{39}$. Por outro lado, chama a atenção a baixa convergência positiva da esquerda em contraste com aquela obtida pelo Executivo, ocupado predominantemente pelo PT e com participação de outros partidos de esquerda, na maior parte do período aqui contemplado.

Por fim, quando consideramos a autoria das proposições pelos partidos divididos em governo e oposição, verificamos que, embora os partidos da base do governo, assim como ocorre com o Executivo, chamem mais a atenção da CNI, isso não implica necessariamente, ao menos no período aqui considerado, maior proximidade com os interesses da entidade, dado que a convergência foi predominantemente negativa, diferentemente das proposições vindas do Executivo, cuja convergência foi predominantemente positiva, além do fato de que mais de um quarto de projetos oriundos dos partidos do governo estavam em divergência com a CNI. Durante o primeiro mandato de Dilma Rousseff houve certa queda das decisões legislativas, mas que não implicou alterações profundas dos demais dados.

Em suma, a ausência de relações mais fortes entre espectro ideológico e posição na relação governo/oposição sugere a hipótese de que tais aspectos podem estar relacionados à complexificação e à profissionalização do formato institucional e ao aprendizado por parte dos industriais a respeito da luta parlamentar e do jogo democrático, reforçando o pragmatismo decorrente da busca da defesa dos interesses e da prática e do conhecimento dos meandros do processo legislativo, adquirido através da construção e operacionalização da AL. Isso reforça a ideia de que a atuação parlamentar da CNI é fortemente marcada tanto pela dinâmica de interesses de seus representados quanto pelos aspectos institucionais do sistema político, em especial a predominância legislativa do Poder Executivo, a despeito de não ocorrer o mesmo com os partidos da própria base desse governo.

\section{Considerações finais}

Quando consideramos a produção acadêmica sobre empresariado e política, verificamos que predomina a questão da força política. Se, por um lado, esse não é o nosso objetivo, por outro, foi o debate com trabalhos importantes dessa literatura que nos moveu no sentido de trazer uma abordagem diferente, a qual possa também contribuir para a construção de agendas de análise das relações de causa e efeito da ação e dos resultados dos processos decisórios na política e, assim, da questão da força política. Mais uma vez, essa contribuição se dá em torno das categorias formato institucional e representação, as

\footnotetext{
39 Gava et al. (2017), ao analisarem a relação entre grupos de interesse e parlamento na Suíça, constatam que o empresariado (business groups) tendia a se articular com os partidos de direita (Gava et al., 2017). A despeito das diferenças entre Brasil e Suíça, podemos destacar que é grande a importância das entidades de representação de interesses empresariais na política e na economia desse país. Sobre isso, ver David et al. ( 2009).
} 
quais tentam articular a análise de aspectos da construção da agenda com a descrição e a avaliação dos resultados dessa agenda no processo decisório.

A pesquisa que embasa este artigo aponta que, em primeiro lugar, a CNI se vê como muito bem-sucedida em sua relação com o Legislativo federal e que o cotejamento entre suas posições e o resultado do processo legislativo indica que tal diagnóstico tem seus fundamentos internos à entidade. Em suma, as taxas de convergência, negativa ou positiva, sempre são maiores do que as de divergências. Nesse sentido, a entidade parece colocar de forma pragmática a questão de sua força política, dado que conclui que houve um resultado favorável aos seus interesses no processo legislativo, mas sem relacioná-lo diretamente à sua ação.

Esse é um elemento importante para pensarmos as agendas de análise da ação e também da força política: trata-se de um agente que se entende e se apresenta como satisfeito com sua ação e se sente forte e protagonista e possui suas razões para tal avaliação. Não se trata de aceitar essa autoatribuição como descrição objetiva da realidade, mas sim de reconhecer a importância dessa constatação para pensar a relação de proximidade e de satisfação por parte desse grupo do empresariado com a democracia, mais particularmente através de sua relação com o Legislativo. Assim, ainda que não pretendamos fazer um estudo do fenômeno do crescimento da importância do Legislativo, convém que, em tal agenda, se considerem não apenas os aspectos institucionais, mas também as relações e o grau de satisfação de grupos sociais importantes com essa instituição fundamental da democracia.

A descrição que a CNI faz do processo de criação e funcionamento da $A L$, aspecto fundamental do formato institucional de sua relação com o Congresso Nacional, revela que, do ponto de vista do próprio ator, havia a necessidade de responder às questões políticas colocadas pela retomada da democracia e às questões econômicas colocadas pelo que se entendia ser o custo Brasil ${ }^{40}$. As variáveis escolhidas pela CNI para caracterizar as proposituras e sua relação com os interesses da entidade indicam o que ela julga mais importante na análise do que acontece no Congresso Nacional.

Como observado acima, não se trata de aceitar o ponto de vista do ator, mas sim de tratá-lo como fator importante para a compreensão de sua ação concreta e de sua relação com as instituições, o que, por sua vez, tem impacto no funcionamento destas. Além disso, evita a simples inferência de que, em sendo um grupo economicamente poderoso, institucionalmente organizado e que avalia positivamente os resultados dos processos políticos, possui força política. A verificação da força política é uma questão fundamental da ciência política que dispensa maiores apresentações, mas este artigo sugere que uma mera resposta positiva ou negativa está longe de ser sociologicamente satisfatória.

40 Sobre essa questão, ver Mancuso (2007a). 
Entretanto, estudar como o ator constrói a sua agenda de interesses e avalia a sua ação é um aspecto fundamental na análise de sua ação e de sua força política, pois, se é importante o analista avaliar sociologicamente a força política de um dado ator, é necessário saber o que o próprio ator pretende, o que coloca como suas metas e como avalia o resultado da ação. Independentemente dos critérios que o analista utiliza para pensar sobre a força de um ator, o que este pensa de sua força é crucial.

Assim, a AL e os demais processos correlatos à relação entre a CNI e o Congresso Nacional revelam o reconhecimento por parte da CNI da necessidade de um maior protagonismo seu no Poder Legislativo federal e, algo ainda a ser verificado, de um maior protagonismo do Poder Legislativo federal na política brasileira. Além disso, mostra que esse protagonismo era entendido como algo que passava pela mobilização não apenas de seus representados diretos, como também de outros segmentos da indústria, expressa de forma intensa na própria AL e no Seminário RedIndústria. E, se tal processo visava à divulgação das posições da entidade e era tido como parte de sua estratégia de ação, não deixava de ser condicionado pelos seus aspectos institucionais formais internos, o formato institucional, no caso, a aprovação das posições pela diretoria da CNI.

Diferentemente do ponto de vista da própria entidade e de seus associados, para o analista, o aspecto mais relevante não é o meramente institucional ou o grau de convergência, mas sim aquilo que esses fatores revelam acerca do aprendizado que cada um dos envolvidos, sejam os próprios industriais, os diretores da entidade, os funcionários e técnicos ou a instituição como um todo, tem que desenvolver para participar do jogo democrático, que vai desde o âmbito interno a cada entidade que participa do processo até o resultado do complexo jogo político. Tal aspecto remete à questão das bases sociais da democracia, para além da análise do funcionamento das instituições e dos levantamentos sobre atitudes e valores democráticos, dado que se refere ao funcionamento concreto da dinâmica institucional de articulação de interesses sociais. Isso é ainda mais relevante quando se trata de uma democracia ainda em processo de consolidação.

Por fim, além do que já foi colocado acima, um dos ganhos que a análise do formato institucional, da representação e da convergência possibilita é o de sugerir outros problemas de pesquisa sobre a ação política e sua efetividade por parte da CNI, dos quais podemos destacar alguns pontos que podem ser levantados visando ao desenvolvimento dessa agenda em estudos posteriores:

- Considerar possíveis desdobramentos da AL nos Legislativos estaduais através de articulações com as entidades estaduais do setor industrial;

- Verificar como se dá a relação com o Poder Executivo e como ela se articula com a atuação no Legislativo; 
- Considerar, em perspectiva comparada os governos, a relação entre as proposições e os partidos políticos quando estão no governo ou na oposição, ampliando no tempo o que aqui foi feito de forma mais restrita;

- Analisar o conteúdo dos projetos, permitindo pensar, por exemplo, nos segmentos da indústria que são mais ou menos contemplados e em projetos mais ou menos convergentes;

- Através de estudos de caso, verificar a ocorrência de relações de causa e efeito que permitam pensar de forma mais precisa e mais bem delimitada não apenas a questão da eficácia da ação ou da força política, mas também a forma como isso se daria. Tal estudo poderia ocorrer de forma comparativa com outros segmentos do empresariado e mesmo dos trabalhadores;

- Debater com a literatura sobre lobbies e grupos de interesse empresariais no âmbito do Poder Legislativo, no sentido de comparar procedimentos e resultados relativos a outras entidades, empresariais ou não, e outros contextos, para aprimorar a abordagem aqui proposta $^{41}$;

- Quanto à análise dos padrões de ação política, este artigo sugere que podemos começar considerando a classificação que a própria entidade faz de seu comportamento ante as proposituras $^{42}$;

- Ainda sobre os padrões de ação política, pode-se analisar a atuação da CNI nas diversas dimensões do processo decisório, seja no Executivo, por exemplo, a presidência da República, os ministérios, as secretarias etc., seja no Legislativo, ou seja, os partidos, as lideranças, as comissões etc.;

- Verificar o impacto do corpo técnico-burocrático das entidades não apenas sobre o seu funcionamento, mas também sobre a definição da agenda de interesses e das estratégias de ação, o que, por sua vez, impacta a ação efetiva;

- O grande número de projetos em convergência poderia sugerir que a atuação mais bemsucedida da CNI é a de obstaculizar as propostas divergentes, dado que, quando

\footnotetext{
41 Apenas a título de exemplo, Dür, Bernhagen e Marshall (2015), tomando por referência o Parlamento Europeu, afirmam que a atuação de grupos empresariais não tem sido mais bem-sucedida do que a de outros grupos organizados da sociedade, embora tendam a ter mais sucesso quando a disputa envolve menos interesses em conflito, menos oposição e menor número de autoridades envolvidas.

42 Apenas a título de ilustração, a partir de 2015, os relatórios da CNI passaram a classificar o comportamento da entidade da seguinte forma: "1. A CNI acompanha; 2. A CNI apoia; 3. A CNI apoiou; 4. A CNI monitora; 5. A CNI trabalhou; 6. A CNI elaborou; 7. Questões conjunturais (quando a CNI não diz o que fez, mas como está a conjuntura da matéria no Legislativo do ponto de vista de sua agenda); 8 . Ações estão sendo feitas; 9. A Coal elaborou; 10. Acompanhamento no sentido de; 11. Articulação no sentido de; 12 . As ações da CNI acompanham as recomendações; 13 . Estratégias regimentais (como a apensação de projetos e redistribuição para nova comissão); 14. Elaboração e entrega de material técnico ao relator; 15 . Material técnico e argumentação foram levados a parlamentares membros da Comissão; 16 . Nota técnica elaborada e apresentada ao novo relator. 17. Material técnico foi elaborado e encaminhado ao relator (parlamentares com interesse no tema foram contatados para solicitar a relatoria do projeto); 18. Parlamentares com interesse no tema foram instados a solicitar a relatoria da proposta; 19. Vigilância permanente de setores contrários à matéria inibiu as ações que tentavam sua aprovação; 20. Realizadas ações e gestões de monitoramento; 21 . Realizadas gestões junto ao relator com apresentação de material técnico ao relator para subsidiar seu parecer". Fonte: CNI. Disponível em: <http://www.portaldaindustria.com.br/cni/canais/agenda-legislativa-home/>. Acesso em: 15 jun. 2017.
} 
consideramos o que foi finalizado, a convergência negativa é maior, embora a diferença em relação à convergência positiva não seja muito grande, como a própria entidade reconhece;

- A análise da origem dos projetos levanta a hipótese de que a CNI se volta mais intensamente para o Executivo no que tange ao processo legislativo. Embora isso não seja surpreendente quando se considera o sistema político brasileiro, é interessante ter esses dados como referência para a análise da sua atuação e do que seria a sua taxa de sucesso, o que somente poderia ser verificado em uma análise das possíveis relações de causa e efeito da ação da CNI no processo legislativo.

O desenvolvimento dessa agenda de pesquisa permite repensar e atualizar questões clássicas e categorias analíticas constitutivas dos estudos sobre o empresariado, como, por exemplo, o corporativismo, a ausência de entidades de cúpula, a fragmentação ou segmentação da sua representação política, o poder de veto $x$ o poder de iniciativa etc., as quais se associam também a outros grupos sociais, como os trabalhadores e as próprias instituições do regime político democrático. Além disso, chama a atenção para a falta de iniciativa da CNI em propor projetos, em especial que tenham alguma natureza de reforma política, ou seja, que impliquem alterações dos formatos institucionais do processo legislativo na democracia brasileira, o que remete à hipótese de relevante grau de satisfação dessa entidade com tais formatos ou, no mínimo, de acomodação ou desinteresse em considerar tais alterações como objeto de sua efetiva ação política.

Enfim, entre os objetivos deste artigo está o de contribuir para o tratamento de um tema e de um objeto que são clássicos nos estudos sobre empresariado no Brasil, ou seja, a ação política dos empresários, industriais ou de outros setores, no contexto democrático. Além de apresentar as categorias analíticas, os dados e as análises aqui propostas, nossa intenção é colaborar com a produção de boas e eficazes hipóteses de trabalho e para a construção de ferramentas e procedimentos analíticos que orientem novas pesquisas.

Entendemos que essa é uma forma de aprimorar a sociologia política da democracia no Brasil, ao estudar as características institucionais da ação política organizada de um relevante grupo econômico e o impacto da condição social sobre as formas institucionais, sejam aquelas internas ao grupo, sejam as do regime político democrático, ou mesmo aquelas relacionadas à cultura política democrática.

\section{Referências bibliográficas}

BAUeR, M. W.; GASKeLL, G. Pesquisa qualitativa com texto - Imagem e som: um manual prático. Petrópolis: Vozes, 2002.

BezerRA, G. M. L. A oposição nos governos FHC e Lula: um balanço da atuação parlamentar na 
EMPRESARIADO, PARLAMENTO E DEMOCRACIA: A CNI E O CONGRESSO NACIONAL (2010-2017)

Câmara dos Deputados. Porto Alegre: UFRGS, 2012.

BRAGA, S.; NiColás, M. A. "Os empresários, a política e a web: mapeando as atividades políticas nos portais das federações de indústrias brasileiras". Sociedade e Estado, vol. 24, no 2, p. 439-490, ago. 2009.

CAMPOS, J. I. "Lobby e parlamento: estudo de caso da atuação da assessoria de relações governamentais da Fiesp no Congresso Nacional brasileiro". Brasília, Câmara dos Deputados, Centro de Formação, Treinamento e Aperfeiçoamento (Cefor), 2017.

CESÁRIO, P. S. "Redes de influência no Congresso Nacional: como se articulam os principais grupos de interesse". Revista de Sociologia e Política, vol. 24, no 59, p. 109-127, set. 2016.

CNI. Agenda Legislativa da Indústria - Prestando Contas. Brasília, 2012. Disponível em: <https://bucket-gw-cni-static-cms-si.s3.amazonaws.com/media/filer_public/7b/d6/7bd6545e-d991448a-a48e-3fddb504c21a/20120912101236820303a.pdf>. Acesso em: 27 ago 2019.

. Agenda Legislativa da Indústria - Prestando Contas. Brasília, 2013. Disponível em: <https://bucket-gw-cni-static-cms-si.s3.amazonaws.com/media/filer_public/7c/f5/7cf5e966-5ea14405-883d-6c6e538cdb72/201308201410494255680.pdf>. Acesso em: 27 ago 2019.

. Agenda Legislativa da Indústria - Prestando Contas. Brasília, 2015. Disponível em: <https://bucket-gw-cni-static-cms-si.s3.amazonaws.com/media/filer_public/f9/1e/f91e86d9-e196424f-81d4-bbece1e6b2d4/prestandocontas2015_documentofinal.pdf>. Acesso em: 27 ago 2019.

CostA, P. R. N. Democracia nos anos 50: burguesia comercial, corporativismo e parlamento. São Paulo: Hucitec, 1998.

. "A elite empresarial e as instituições democráticas: cultura política, confiança e padrões de ação política". Opinião Pública, vol. 18, no 2, p. 452-469, 2012.

DAVID, T., et al. "Networks of coordination: Swiss business associations as an intermediary between business, politics and administration during the 20th century". Business and Politics, vol. 11, n 4, p. 1-38, 20 dez. 2009.

DIAP. Radiografia do novo Congresso: legislatura 2015-2019. Brasília: Diap, 2014.

DOCTOR, M. "Business and delays in port reform in Brazil". Brazilian Journal of Political Economy, vol. 22, no 2, p. 79-86, 2002.

DonATELLO, L. M. "Legisladores representantes empresariales en Argentina y Brasil: la emergencia de una categoría de especialistas". Revista de Sociologia e Política, vol. 25, no 63, p. 139-158, set. 2017.

Dür, A.; Bernhagen, P.; MARShall, D. "Interest group success in the European Union". Comparative Political Studies, vol. 48, no 8, p. 951-983, 20 jul. 2015.

Figueiredo, A.; Limongi, F. Executivo e Legislativo na nova ordem constitucional. Rio de Janeiro: Fundação Getúlio Vargas, 1999.

. Que instituições políticas importam e para que importam: lições dos estudos legislativos no Brasil. In: Lavalle, A. G. (org.). Horizonte da política: questões emergentes e agendas de pesquisa. São Paulo: Unesp, 2012.

2017. . "A crise atual e o debate institucional". Novos Estudos Cebrap, vol. 36, no 3, p. 79-97,

GAVA, R., et al. "Interests groups in parliament: exploring MPs' interest affiliations (2000-2011)". 
Swiss Political Science Review, vol. 23, no 1, p. 77-94, mar. 2017.

InglehART, R. "The renaissance of political culture". The American Political Science Review, vol. 82, no 4, p. 1.194-1.203, dez. 1988.

Krause, S.; Rebello, M. M.; Silva, J. G. "O perfil do financiamento dos partidos brasileiros (20062012): autores, objetivos, êxito e fracasso (1988-2010)". Revista Brasileira de Ciência Política, no 16, 2015.

MAncuso, W. P. "O lobby da indústria no Congresso Nacional: empresariado e política no Brasil contemporâneo". Dados, vol. 47, no 3, p. 505-547, 2004.

$2007 a$. . O lobby da indústria no Congresso Nacional. São Paulo: Edusp/Humanitas/Fapesp,

\begin{abstract}
. "O empresariado como ator político no Brasil: balanço da literatura e agenda de pesquisa". Revista de Sociologia e Política, no 28, p. 131-146, 2007b.

Mancuso, W. P.; Oliveira, A. J. "Abertura econômica, empresariado e política: os planos doméstico e internacional". Lua Nova, vol. 69, 2002.

OLIVEIRA, A. C. J. "Lobby e representação de interesses: lobistas e seu impacto sobre a representação de interesses no Brasil". Tese de doutorado em ciências sociais. Universidade Estadual de Campinas, Campinas, 2004.
\end{abstract}

OliVeIRA, A. J.; ONUKI, J. Política comercial e Legislativo: a atuação do empresariado brasileiro. In: MANCuSo, W. P.; LeOPOldi, M. A.; IgleciAs, W. (eds.). Estado, empresariado e desenvolvimento no Brasil: novas teorias, novas trajetórias. São Paulo: Editora de Cultura, 2010.

OLson, M. A lógica da ação coletiva. São Paulo: Edusp, 1999.

Perissinotto, R.; Stumm, M. G. "A virada ideacional: quando e como ideias importam". Revista de Sociologia e Política, vol. 25, no 64, p. 121-148, dez. 2017.

PONT, J. V. Empresariado industrial, ação política e legislação social no Brasil (1930-1988). Porto Alegre: Armazém Digital, 2008.

SANTOS, M. L. W. D. "O parlamento sob influência: o lobby da indústria na Câmara dos Deputados". Tese de doutorado em ciência política. Universidade Federal de Pernambuco, Pernambuco, 2011.

. "Representação de interesses na Câmara dos Deputados: o lobby e o sucesso da agenda legislativa da indústria". Revista Ibero-Americana de Estudos Legislativos, vol. 3, no 1, 1 jan. 2014.

SANTOS, M. L., et al. "Financiamento de campanha e apoio parlamentar à agenda legislativa da indústria na Câmara dos Deputados". Opinião Pública, vol. 21, no 1, p. 33-59, abr. 2015.

SCHNEIDER, B. R. Business politics and the State in twentieth-century Latin-America. Cambridge: Cambridge University Press, 2004.

. Business politics in Latin America: patterns of fragmentation and centralization. In: COEN, D.; GRANT, W.; WILSON, G. (eds.). The Oxford handbook of business and government. Oxford: Oxford University Press, 2010.

SzWAKo, J.; MourA, R.; D'AVILA Filho, P. Estado e sociedade no Brasil: a obra de Renato Boschi e Eli Diniz. Rio de Janeiro: Faperj/INCT/PPED/Idea D, 2016.

Troiano, M. "As associações empresariais e o Processo Constituinte de 1987-1988". Dissertação de 
mestrado em ciência política. Universidade de São Carlos, São Carlos, 2012.

. "Os empresários no Congresso: a legitimação de interesses via audiências públicas". Tese de doutorado em ciência política. Universidade de São Carlos, São Carlos, 2017.

\begin{abstract}
Business, parliament and democracy: CNI and the National Congress (2010-2017)

The article deals with the relationship between entrepreneurs and Parliament in Brazil, more specifically the Legislative Agenda of the National Confederation of Industry (CNI). The objective is to check the particularities of the process of constituting industrialists as political actors in Parliament from analytical categories focused on 1) the internal institutional process of the CNI as regards defining its positions on the projects in progress, 2) the way the entity describes and evaluates its relationship with the Federal Legislative Branch, and 3) a comparison between such positions and the results of the legislative process. The public documents of the CNI, processed in a quantitative and qualitative manner, were used, considering the period from 2010 to 2017. We have verified that the particularities of the relationship between industrialists and Parliament indicate the complexity of the process of their constitution as a political actor in the legislative process, the importance given to such a process and the high degree of satisfaction with the form and results of this relationship, allowing us to think about the characteristics of this institution also in the light of the relationship established with it by an important social group, as well as on the concrete functioning and social bases of Brazilian Democracy. Keywords: businessmen; National Congress; National Confederation of Industry; Seminar RedIndustry; lobbying
\end{abstract}

\title{
Resumen
}

Emprendedores, parlamento y democracia: CNI y el Congreso Nacional (2010-2017)

Este artículo aborda la relación entre las empresas y el parlamento en Brasil, específicamente la Agenda Legislativa de la Confederación Nacional de la Industria (CNI). El objetivo es verificar las particularidades del proceso de constitución del industrial como actor político en el Congreso Nacional a partir de categorías analíticas dirigidas a: 1) el proceso institucional interno del CNI al definir sus posiciones en los proyectos; 2 ) cómo la entidad describe y evalúa su relación con el parlamento; y 3) la comparación entre tales posiciones y los resultados del proceso legislativo. Se utilizaron los documentos públicos del CNI, procesados de manera cuantitativa y cualitativa, considerando el período de 2010 a 2017. Verificamos que las particularidades de la relación entre industriales y el parlamento indican la complejidad del proceso de constitución de aquellos como actor político en la legislación, la importancia dada por parte de este actor ante dicho proceso y su alto grado de satisfacción con la forma y resultados de su relación con el Congreso Nacional, lo que permite pensar en las características de esta institución también a la luz de la relación que establece con ella un importante grupo de la sociedad, así como qué hay de su funcionamiento concreto y las bases sociales de la democracia en Brasil.

Palabras clave: comunidad empresarial; Congreso Nacional; Confederación Nacional de Industria; Seminario RedIndustria; lobby

\section{Résumé}

Entrepreneurs, parlement et démocratie: la CNI et le Congrès national (2010-2017)

Cet article traite des relations entre les entreprises et le parlement au Brésil, et plus particulièrement du programme législatif de la Confédération nationale de l'industrie (CNI). L'objectif est de vérifier les particularités du processus de constitution de l'entrepreneuriat industriel en tant qu'acteur politique du Congrès national à partir de catégories analytiques visant à : 1) le processus institutionnel interne au CNI consistant à définir ses positions sur les projets; 2) comment l'entité décrit et évalue ses relations avec le parlement; et 3 ) la comparaison entre ces positions et les résultats du processus législatif. Les documents publics du CNI ont été utilisés, traités de manière quantitative et qualitative, en tenant compte de la période allant de 2010 à 2017. Nous avons vérifié que les particularités de la 
relation entre industriels et parlement témoignaient de la complexité du processus de constitution de ceux-là en tant qu'acteur politique au sein du législatif, de I'importance que donne cet acteur à ce processus et son haut degré de satisfaction envers la forme et des résultats de sa relation avec le Congrès national, ce qui permet de réfléchir aux caractéristiques de cette institution à la lumière de la relation qu 'un groupe important de la société établit avec elle, de même qu'à son fonctionnement concret et aux bases sociales de la démocratie au Brésil.

Mots-clés: entrepreneurs; Congrès national; Confédération Nationale de l'industrie; Séminaire RedIndustria; lobby

Artigo submetido à publicação em 7 de junho de 2018. Versão final aprovada em 17 de julho de 2019.

Opinião Pública adota a licença Creative Commons CC-BY. 